\title{
Capturing the behavioural determinants behind the adoption of autonomous vehicles: conceptual frameworks and measurement models to predict public transport, sharing and ownership trends of self-driving cars
} Dol:

10.1016/j.trf.2019.01.009

\section{Document Version}

Accepted author manuscript

Link to publication record in Manchester Research Explorer

Citation for published version (APA):

Acheampong, R. A., \& Cugurullo, F. (2019). Capturing the behavioural determinants behind the adoption of autonomous vehicles: conceptual frameworks and measurement models to predict public transport, sharing and ownership trends of self-driving cars. Transportation Research. Part F: Traffic Psychology and Behaviour, 62, 349375. https://doi.org/10.1016/j.trf.2019.01.009

\section{Published in:}

Transportation Research. Part F: Traffic Psychology and Behaviour

\section{Citing this paper}

Please note that where the full-text provided on Manchester Research Explorer is the Author Accepted Manuscript or Proof version this may differ from the final Published version. If citing, it is advised that you check and use the publisher's definitive version.

\section{General rights}

Copyright and moral rights for the publications made accessible in the Research Explorer are retained by the authors and/or other copyright owners and it is a condition of accessing publications that users recognise and abide by the legal requirements associated with these rights.

\section{Takedown policy}

If you believe that this document breaches copyright please refer to the University of Manchester's Takedown Procedures [http://man.ac.uk/04Y6Bo] or contact uml.scholarlycommunications@manchester.ac.uk providing relevant details, so we can investigate your claim.

\section{OPEN ACCESS}


Capturing the behavioural determinants behind the adoption of autonomous vehicles: conceptual frameworks and measurement models to predict public transport, sharing and ownership trends of self-driving cars

\section{Dr. Ransford A. Acheampong}

Presidential Academic Fellow in Future Cities

Department of Planning and Environmental Management

University of Manchester.

Oxford Road.

Email: ransfordantwi.acheampong@manchester.ac.uk

Dr. Federico Cugurullo

Assistant Professor (Smart and Sustainable Urbanism)

Trinity College, Dublin, the University of Dublin,

Department of Geography.

Museum Building, Dublin 2, Ireland.

Email: Cugurulf@tcd.ie

This is the authors' version of the original article accepted in Transportation Research Part F: Psychology and Behaviour

Accepted 10 January 2019. 


\begin{abstract}
Autonomous Vehicles (AVs) have the potential to make motorized transport safer and more sustainable, by integrating clean technologies and supporting flexible shared-mobility services. Leveraging this new form of transport to transform mobility in cities will depend fundamentally on public acceptance of AVs, and the ways in which individuals choose to use them, to meet their daily travel needs. Empirical studies exploring public attitudes towards automated driving technologies and interest in AVs have emerged in the last few years. However, within this strand of research there is a paucity of theory-driven and behaviourally consistent methodologies to unpack the determinants of user adoption decisions with respect to AVs. In this paper, we seek to fill this gap, by advancing and testing four conceptual frameworks which could be deployed to capture the range of possible behavioural influences on individuals' AV adoption decisions. The frameworks integrate socio-demographic variables and relevant latent behavioural factors, including perceived benefits and perceived ease of use of $A V s$, public fears and anxieties regarding AVs, subjective norm, perceived behavioural control, and attitudinal factors covering the environment, technology, collaborative consumption, public transit and car ownership. We demonstrate the utility and validity of the frameworks, by translating the latent variables into indicator items in a structured questionnaire, and administering it online to a random sample of adult individuals $(n=507)$. Using the survey data in confirmatory factor analyses, we specify and demonstrate scale reliability of indicator items, and convergent and discriminant validity of relationships among latent variables. Ultimately, we advance four measurement models. These theory-grounded measurement models are intended for application in research aimed at understanding and predicting (a) AV interest and adoption intentions, and (b) user adoption decisions regarding three different $\mathrm{AV}$ modes: ownership, sharing and public transport.
\end{abstract}

Key words: autonomous vehicles; self-driving cars; driverless cars; user adoption; travel behaviour; attitudes; public acceptance; collaborative consumption; perceived benefits 


\section{Introduction}

With the rapid advancement in vehicle automation technology, driverless cars are becoming operational in a number of countries (Duarte and Ratti, 2018; Gandia et al., 2019; Karvonen et al., 2018). Fully-autonomous Vehicles (FAVs) and Connected Autonomous Vehicles (CAVs) are expected to assume safety-critical control functions efficiently, either within a prescribed operation domain (i.e. Level-4 automation) or in a real-life environment under normal road conditions (i.e. Level-5 automation) (NHTSA, 2013). Autonomous transport will substantially reshape motorized transportation in cities. By replacing the human driver with advanced sensing and communication technology, FAVs can potentially reduce crashes and fatalities (Fagnant and Kockelman, 2015; Hashimoto et al., 2016) and increase accessibility levels in cities (Milakis et al., 2017). Deployed through shared-mobility schemes, AVs could also meet the travel needs of users, whilst contributing to the reduction of the negative travel-induced impacts on land use, energy use, traffic, biodiversity and public health (Chan, 2017; Sivak and Schoettle, 2015; Zhang et al., 2017; Crayton et al., 2017).

Ultimately, the extent of the potential changes triggered by autonomous transport, is directly linked to public acceptance, and the ways in which people choose to use the technology to meet their travel needs. Public acceptance and adoption of AVs relate and depend upon a complex network made of heterogeneous potential users who possess different attitudes, perceptions, motivations, preferences, socio-demographic attributes and mobility needs. Moreover, individuals act within much broader socio-cultural, economic and political contexts and, as a result, their adoption decisions with respect to AVs, is strongly linked to wider socioeconomic forces (Malikis et al., 2017).

Approaching user acceptance and diffusion of autonomous transport services through this perspective, shows that the study of the behavioural determinants of AV adoption decisions, is a complex and multi-faceted research theme. Therefore, an interdisciplinary methodology is needed to interrogate the wide range of factors that influence adoption decisions. However, the emerging literature on the topic is largely based on narrow methodologies which, despite their scientific contribution, do not fully capture the complexity of the matter. Previous studies (see e.g. Woldeamanuel and Nguyen, 2018; Sanbonmatsu et al., 2018; Daziano et al, 2017; Haboucha et al., 2017; Nair et al., 2017; Bansal et al., 2016; Lavieri et al., 2017; Bansal and Kockelman, 2017; Lavasani et al., 2016; Kyriakidis, et al., 2015; Adnan et al., 2018; Umberger, 2016) have attempted to examine public opinions and to forecast long-term adoption of autonomous mobility technologies, by focusing largely on the financial attributes of driverless technologies, and/or accounting for a limited number of attitudinal factors, such as public safety and privacy concerns and confidence in driverless technologies. Another strand of $A V$ research has sought to estimate optimal vehicle fleet-size on dynamic AV ridesharing systems (Fagmant and Kockelman, 2015), potential effect of AVs on users' daily activities (Pudāne et al., 2018), as well as to assess the land use and environmental impacts of various driverless cars adoption and diffusion scenarios (e.g. Fagmant and Kockelman, 2015; Zhang et al., 2015, 2017; Wadud et al., 2016). Overall, we argue that the 
interrelationships among the several socio-economic, cultural and psychological factors that can influence user adoption behaviour for different AV options, have so far not been given adequate attention in academic literature.

Understanding and predicting user adoption behaviour and diffusion of AVs require a theorygrounded, behaviourally realistic conceptual framework capturing the multiple facets of the phenomenon. An equally important requirement is a robust statistical methodology that allows to specify, validate and quantify a set of hypothesized relationships among latent behavioural concepts derived from the conceptual framework. This paper aims to fill this gap, by assembling and testing four comprehensive conceptual frameworks that can be applied to unpack the possible behavioural influences on user adoption and diffusion of autonomous mobility services. To this end, we synthesize the principles of and the insights from sociopsychological and socio-ecological theories of human behaviour under volitional control and previous models of technology adoption and diffusion, to advance interdisciplinary conceptual frameworks to study adoption of AVs. We also tap into the emerging ethos of collaborative consumption, and integrate in the proposed frameworks environmental sustainability considerations in travel mode choice at the individual level.

Moreover, we identify the key elements of the proposed frameworks, outline the corresponding indicators of latent variables, and translate them into a structured questionnaire. Next, the questionnaire is administered online to a random sample population of 507 adult individuals. We test the overall scale and sub-scale reliabilities and internal consistencies of the indicator items. Ultimately, we develop and advance four measurement models designed for research aimed at understanding and predicting (a) AV interest and adoption intentions, and (b) user adoption decisions regarding three different AV modes: ownership, sharing and public transport.

The rest of the paper is structured as follows. In section two, we review and synthesize existing theories and models of user adoption behaviour. Building on this synthesis, in section three we advance four interrelated conceptual frameworks for the study of the adoption of self-driving cars. In section four, we discuss the methodology, explaining key aspects of questionnaire design, data collection and statistical modelling techniques. In section five, we present the results of the statistical modelling and propose four related measurement models. Finally, we conclude the paper by discussing the main findings and their implications for future research on autonomous cars.

\section{Synthesizing existing theories and models of user adoption}

\subsection{Socio-psychological and Socio-ecological models of behaviour under volitional control}

Theories from social-psychology and social-ecology have provided robust frameworks to understand the influence of multiple factors on different types of behaviours under volitional 
control. The Theory of Planned Behaviour (TPB) (Ajzen, 1991) and the Socio-Ecological Model of behaviour (McLeroy et al., 1988), although originally intended for application in healthrelated behaviours, have proved useful in understanding the influence of individual-level attitudinal factors, and external social and physical environment factors on travel behaviours, including conventional motorized and active travel choices (see e.g. Kroesen and Chorus, 2018; Sigurdardottir et al., 2013; Bamberg et al., 2003; Haustein and Hunecke, 2007).

TPB posits that intentions precede behaviour and that behavioural intentions are proximally linked to three key latent concepts, namely attitude toward the behaviour, perceived behavioural control (PBC) and subjective norm (SN)-see figure 1a. Attitudes reflect an individual's expectation of the outcomes of an activity, and the personal values that are attached to them (Ajzen, 1991; Sutton et al., 2003). Attitude could be affective (i.e. a person's feelings or emotions about the attitude object e.g. fear, fun or hate) or instrumental (i.e. cognitive consideration of the extent to which performing a behaviour would be beneficial or advantageous) (French et al., 2005; Armitage and Conner, 2001; Sun et al., 2015). PBC reflects an individual's perception of the ease or difficulty of performing a behaviour of interest, such as using new technologies. SN, the last determinant of behaviour in TPB, refers to the norms held by society or a group of people, which influence and regulate behaviour, by functioning as informal social controls (Eves et al., 2003).

While TPB aggregates factors intrinsic to the individual, the socio-ecological perspective (see figure $\mathbf{1 b}$ ) attempts to capture the interrelationships between individuals and their external environments (Sallis et al., 2008). In a typical socio-ecological model applied to travel-related choices, personal factors include socio-demographic characteristics and an individual's knowledge, attitudes and perceptions (see e.g. Acheampong and Siiba, 2018; Elder et al., 2007; Badland et al., 2013; Sigurdardottir et al., 2013). The social environment component would reflect interpersonal processes and primary groups, such as formal and informal social network and social support systems (McLeroy et al., 1988), and the influence of significant others including family, work colleagues and friends, as posited in Ajzen's TPB. The physical environment component is intended to capture, for example, the effect of urban structural variables, such as density, destination accessibility and diversity of land uses (see e.g. Næss, 2015; Ewing and Cervero, 2010), on transport mode choice. Finally, from the socio-ecological perspective we could examine the influence of wider public policies on individuals' travel choices. Such policies may include infrastructure-related investments, public awareness campaigns aimed at changing negative perceptions and attitudes, and incentive-based policy instruments (e.g. subsidies and lower insurance premiums) to promote desired travel choices in the population. 


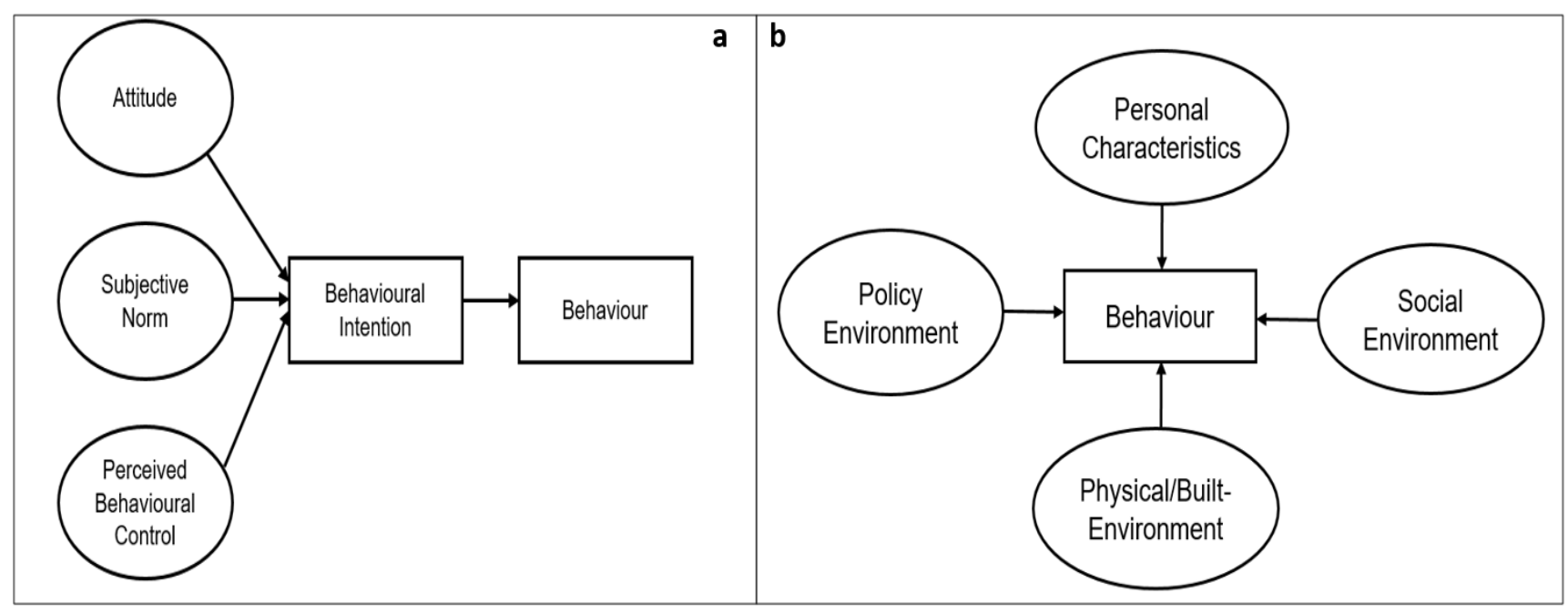

Fig 1: (a) The theory of planned behaviour (b) Socio-ecological model of behaviour

\subsection{Models of technology acceptance and diffusion}

The Technology Acceptance Model (TAM) (Davis et al., 1989) and Technology Diffusion Theory (TDT) (Rogers, 1962, 2000) have provided robust frameworks for understanding user acceptance for new ICT-enabled systems and products in the past. These theoretical frameworks make it possible to identify the heterogeneity in the preferences that underpin adoption decisions, as a function of the interaction between the unique attributes of the technological innovation at play (e.g. driverless cars) and the characteristics of the decisionmakers. The diffusion theory of Rogers is also particularly useful in accounting for the temporal dynamics in individuals' adoption behaviour: an important aspect of the choice process which is required to estimate the diffusion of new innovations such as AVs.

In TAM, two main belief variables determine user acceptance. These are Perceived Usefulness (PU) and Perceived Ease of Use (PEU) of the technology. PU reflects an individual's belief of the extent to which adopting a new technology will enhance the performance of specific tasks or activities. PEU refers to an individual's belief about the extent to which interacting with the new technology will be free of effort. PEU therefore captures the individual's belief regarding (a) the amount of physical and/or mental effort which would be required to use the technology, (b) their ability to get the technology to do what they want it to do, and (c) the general level of clarity and understanding of the use of the technology (Venkatesh and Davis, 2000; Venkatesh et al., 2003). PEU is hypothesized to have direct influence on PU, implying that the usefulness of a new technology depends on its ease of use.

Venkatesh and Davis (2000) extended the original TAM model, by including additional theoretical concepts. They include subjective norm from TPB, in order to capture the influence of significant others on individuals' adoption decisions. Moreover, they introduce two latent concepts, voluntariness and internalization, as mediators of the effect of subjective norm on technology adoption decisions (see Fig 2). They define the former as the 'extent to which potential adopters [of technology] perceive the adoption decision to be nonmandatory', and the latter as 'the process by which when one perceives that an important 
referent thinks one should use a system [or technology], one incorporates the referent's belief into one's own belief structure' (Venkatesh and Davis, 2000 p188).

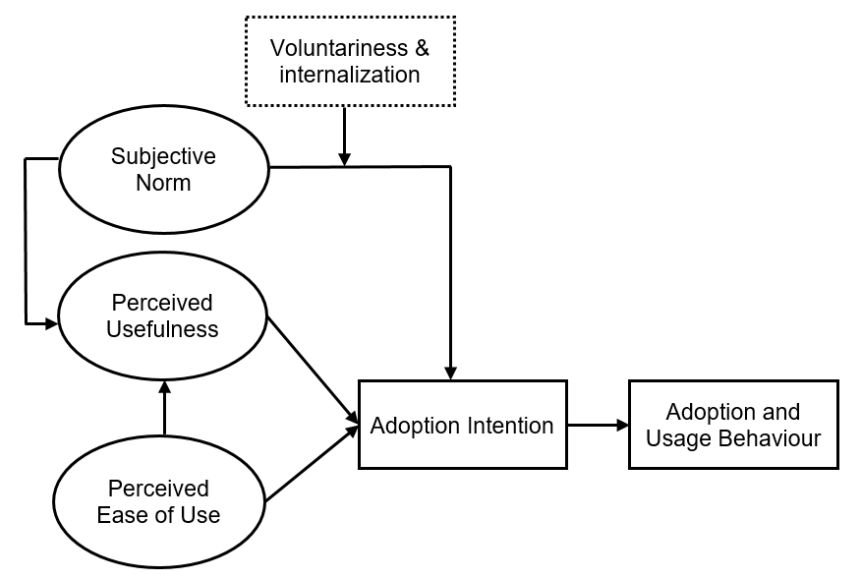

Fig 2: The technology acceptance model incorporating subjective norm from the TPB

Rogers' theory of technology offers a typology of would-be users who make adoption decisions over different time horizons. Five categories of adopters are identified: innovators, early adopters, early majority, late majority and laggards. Innovators tend to be, for example, tech-savvy individuals who adopt new products and services faster than anyone else in the population (Rogers, 2000; Urban \& von Hippel, 1988). Laggards, on the other hand, are the last in the population to adopt an innovation. They tend to have limited financial resources, implying that although they are often perceived as barriers to innovation adoption and diffusion, they consider their resistance to innovation to be the most rational decision to make, in the face of uncertainty (Rogers, 1995). In addition to providing a typology of adopters, Rogers' innovation diffusion theory incorporates six innovation characteristics that influence adoption decisions: relative advantage, status aspects of innovations, compatibility, complexity and trialability.

Moore and Benbasat (1991) developed a unified framework of technology adoption and diffusion called Perceived Characteristics of Innovating (PCI) Belief, by merging elements borrowed from TAM and TDT. PCI maintains three of Rogers' attributes of innovation (relative advantage, compatibility and trialability) and proposes four additional attributes, namely image, visibility, result demonstrability and voluntariness, as determinants of innovation adoption. Plouffe et al., (2001) tested the performance of the PCI belief and TAM frameworks in Smart Card technology adoption. They concluded that $\mathrm{PCl}$ variables capture substantially more variance in the adoption of Smart Card technology, than TAM variables.

\subsection{Collaborative consumption, shared-mobility and environmental sustainability} Shared-mobility models, such as car-sharing services, are closely linked to a much wider movement of anti-consumerism that has come to be known under the umbrella term of collaborative consumption. In Bostman and Rogers' (2010) typology of collaborative consumption systems, car-sharing is identified as a Product Service System: the type of 
collaborative consumption service which enables people to pay for the benefits of products owned by a company without needing to own the products outright. There is growing consensus among experts that deploying driverless cars through shared-mobility services, has the potential of having positive environmental externalities (Schonberger and Gutmann 2013; Litman, 2017; Sivak and Schoettle, 2015). Therefore, the behavioural influences of this emerging consumption trend and its implications for lifestyle adjustments and prevailing cultural values, ought to be examined in studies of user adoption and diffusion of AVs.

Collaborative consumption motivations and barriers have been examined in different consumption contexts, including car-sharing (Bardhi and Echardt, 2012; Hamari et al., 2016) and urban food-sharing systems (Davies et al., 2017). The economic benefits of making and or saving money, trust among participants, highly educated and higher income demographics; reputation, enjoyment and freedom of choice have been established as some of the main determinants of collaborative consumption. The actual impact that environmental concerns have on sharing practise, is uneven. In some studies, it appears that for some participants, sustainability concerns are often of secondary importance (see Barnes and Mattsson, 2016), or emerge as unintended consequences of sharing (Botsman and Rogers, 2010). However, other studies have shown that sharing practices are often employed by individuals, to articulate and promote values which are deeply seated in concerns for environmental issues, such as over-consumption and food and energy waste (Gansky, 2010). In the latter case, ecological and social sustainability motives tend to be some of the key determinants of collaborative consumption (Mont, 2004; Hamari et al., 2016).

In the section that follows, we draw on the theoretical concepts and models discussed above to advance four interconnected conceptual frameworks. In each framework, we (a) indicate a specific aspect of the AV user adoption behaviour question that is being addressed, (b) identify the relevant latent behavioural variables and (c) specify pairs of hypothesized relationships to be tested empirically.

\section{Developing conceptual frameworks}

In this section, building upon the insights discussed above, we conceptualize AV adoption decisions as being at the intersection of four main mutually linked behaviour-influencing forces, operating at the individual and societal levels. These are human choice under volitional control; technological innovation and attributes of the technology; prevailing consumption ethos and practices in transportation such as shared-mobility, and environmental sustainability considerations in transportation. Using these concepts and theories, we propose four conceptual models, each of which is intended to address a specific aspect of the AV user adoption behaviour question. The first conceptual model (CM-1), is our starting framework which is meant to be deployed in cases where the research objective is to understand and predict the behavioural determinants of general interest and adoption intentions regarding driverless vehicles. The remaining three conceptual models addresses adoption behaviour for different AV modes, namely AV-sharing (CM-2), AV-public transport services (CM-3), and AV ownership (CM-4). 
Given the multiplicity of factors involved in understanding the aforementioned aspects of user adoption as well as the several possible theoretical relationships among them that we will later test empirically, we envisage that the proposed conceptual models would be deployed using Structural Equation Modelling (SEM). Consequently, following the structure of SEMs, each of our conceptual models is divided into two parts: Part I is the measurement model, comprising the relevant behavioural concepts and the hypothesized relationships among them, while Part II consists of the structural model or outcome variables, which in the context of this paper, refers to the four aspects of the AV user adoption question outlined above. Below, we explain the conceptual models, outlining the relevant theoretical concepts and the hypothesized relationships among them.

In the basic conceptual model (i.e. CM-1), we identify seven latent behavioural antecedents to AV adoption behaviour (see Fig 3). From the existing models of technology adoption and diffusion, we include individuals' perception of the benefits of AVs, perception of ease of use of $A V s$ and their general attitude towards technology and innovation. Following insights from TPB and technology acceptance models, subjective norm and image are included in our model to reflect the possible influences of external social factors on AV adoption. We also include perceived behavioural control to capture the extent to which individuals believe they have control over whether or not they will use AVs. Finally, we include perceived fears and anxieties as a latent variable to reflect the safety and security implications of AVs from the point of view of would-be users. Eleven sets of hypothesized relationships are depicted in the framework (see Part I of Fig 3). Nine of these are hypothesized associations (indicated by double-headed arrows) for which correlation and covariance estimates would be computed based on empirical data, using Confirmatory Factor Analysis. The remaining three are hypothesized direct effects, for which regression co-efficients will be computed. For example, following the findings of initial exploratory research on the topic (see e.g. Woldeamanuel and Nguyen, 2018; Sanbonmatsu et al., 2018), we hypothesize that there would be an association between attitude towards technology and individuals' perceptions of potential advantages and disadvantages of AVs. In addition to maintaining that subjective norm will have a direct influence on perceived benefits as originally posited in the innovation diffusion and acceptance models, we further hypothesize that in the context of AV-adoption behaviour, subjective norm will also influence perception of ease of use. The underlying assumption is that more individuals would come to believe that AVs are easy to use as they observe others, including relatives, friends and colleagues employ new technology. The reverse is also plausible. Finally, we include socio-demographic factors to capture the possible effects of variables such as age, gender, education and income. While we expect that sociodemographic factors would be relevant, we also acknowledge that the possible effect relationships among these factors and the latent behavioural variables represented in the framework could be many. We therefore reserve showing specific effect relationships among these variables to the point where we specify our measurement models. 


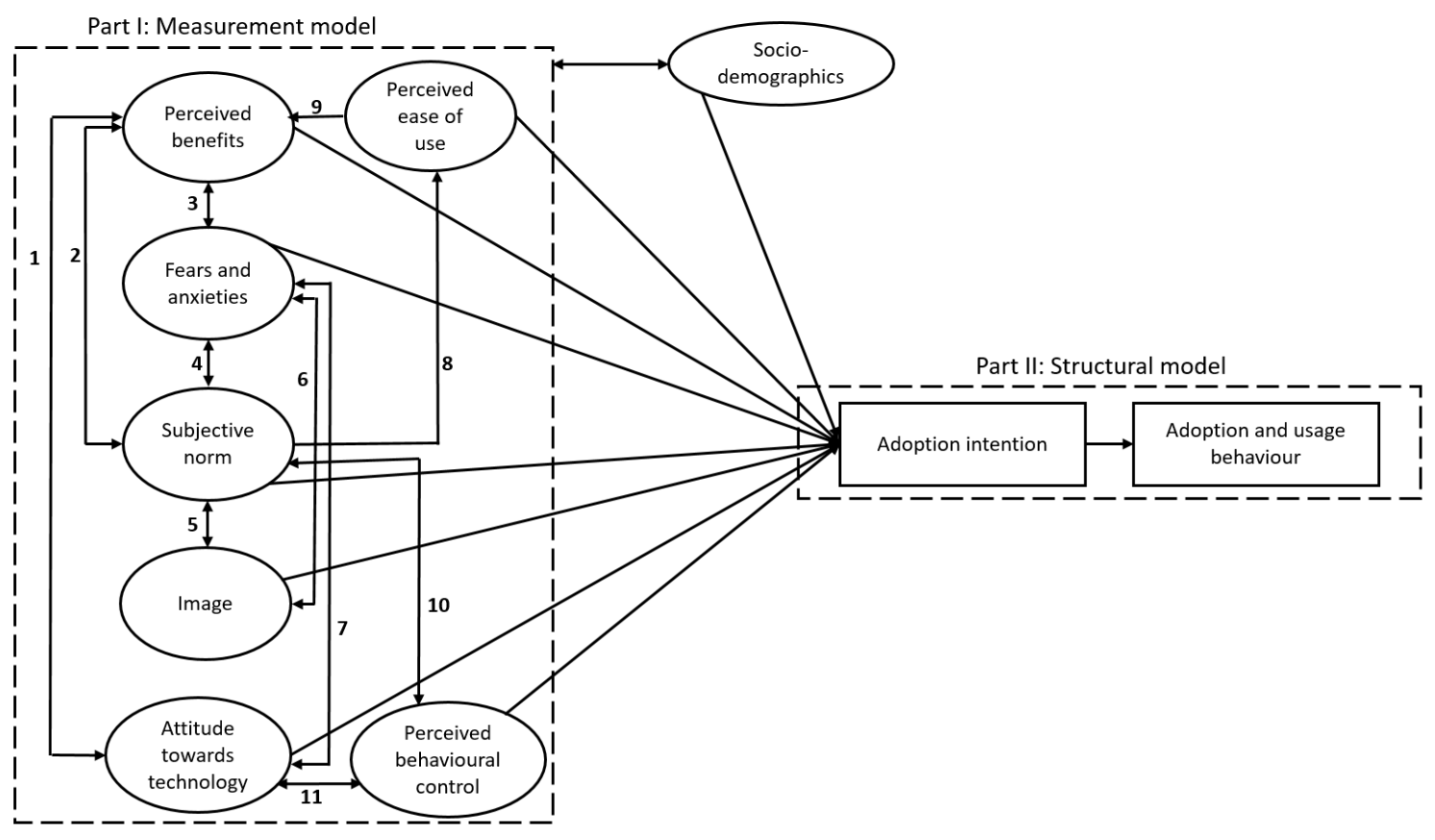

Fig 3: Basic conceptual model of AV user adoption behaviour (CM-1)

Building on the basic conceptual model discussed above, we propose three additional frameworks which are intended to address user adoption behaviour with respect to specific AV modes. Fig 4 shows the conceptual model for understanding and predicting adoption of AV-sharing services (i.e. CM-2). In the measurement model component of the framework, nine latent variables are identified. Given that the focus here is on sharing, it is relevant that we capture individuals' general attitudes towards collaborative consumption. Moreover, travel mode choices have environmental sustainability implications, and car-sharing in particular is expected, among other things, to reduce car ownership and the associated negative impacts on the environment. This implies that individuals' attitude towards the environment would be relevant in understanding whether or not they would want to use carsharing services provided by AVs. Indeed, as the literature review has shown, for some individuals, environmental sustainability persuasions tend to underpin their decision to participate in collaborative consumption models, including car-sharing. In the context of AV acceptance, in particular, an initial exploratory study by Wu et al (2019), suggests that environmental concern have a positive relationship with individuals' intention to use electric driverless cars. In view of this, we introduce two new latent variables, namely attitude towards the environment and attitude towards collaborative consumption in $\mathrm{CM}-2$, in addition to the seven latent variables presented in $\mathrm{CM}-1$. In CM-2, a total of 14 relationships, comprising 12 sets of hypothesized associations and two direct effect relationships are represented in what would later be specified as the measurement model (see Fig 4). 


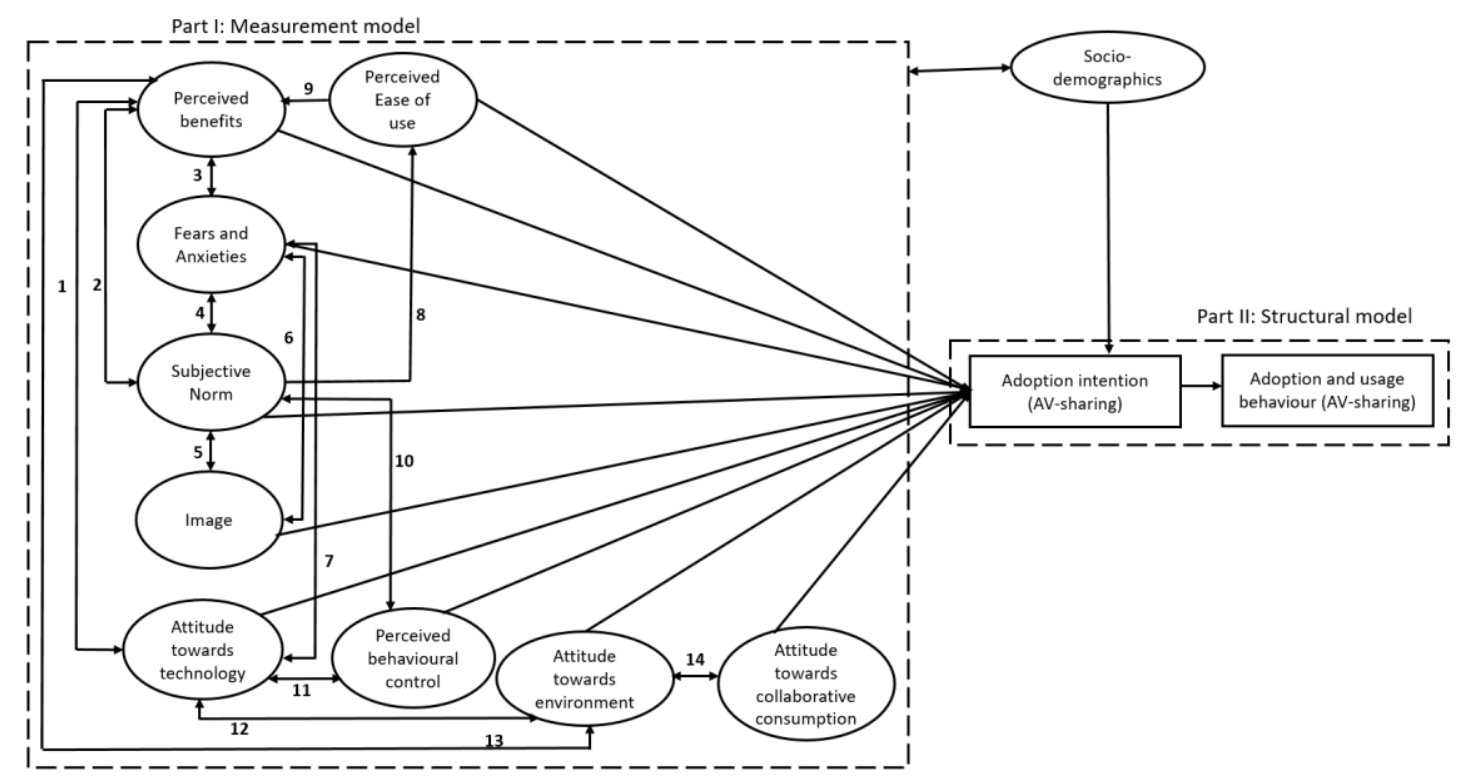

Fig 4: Conceptual model of AV-sharing adoption behaviour (CM-2)

AVs will essentially serve the travel needs that conventional vehicles are currently serving. We therefore expect that the utility derived from existing travel modes such as car ownership/use and public transport, and how these reflect the perceptions of their benefits and disadvantages, would still be relevant irrespective of the technology. In view of this, in the third conceptual model (i.e. CM-3), which is intended for application to understand AV adoption through public transport services, we include individuals' attitude towards public transit (see Fig 5). Similarly, in the fourth conceptual model (i.e. CM-4) which is intended for application to understand AV adoption through ownership, we expect that individuals' attitude towards car ownership/use would be relevant (see Fig 6). In both CM-3 and CM-4, a total of 14 relationships, comprising 12 sets of hypothesized associations and two of direct effect relationships are represented.

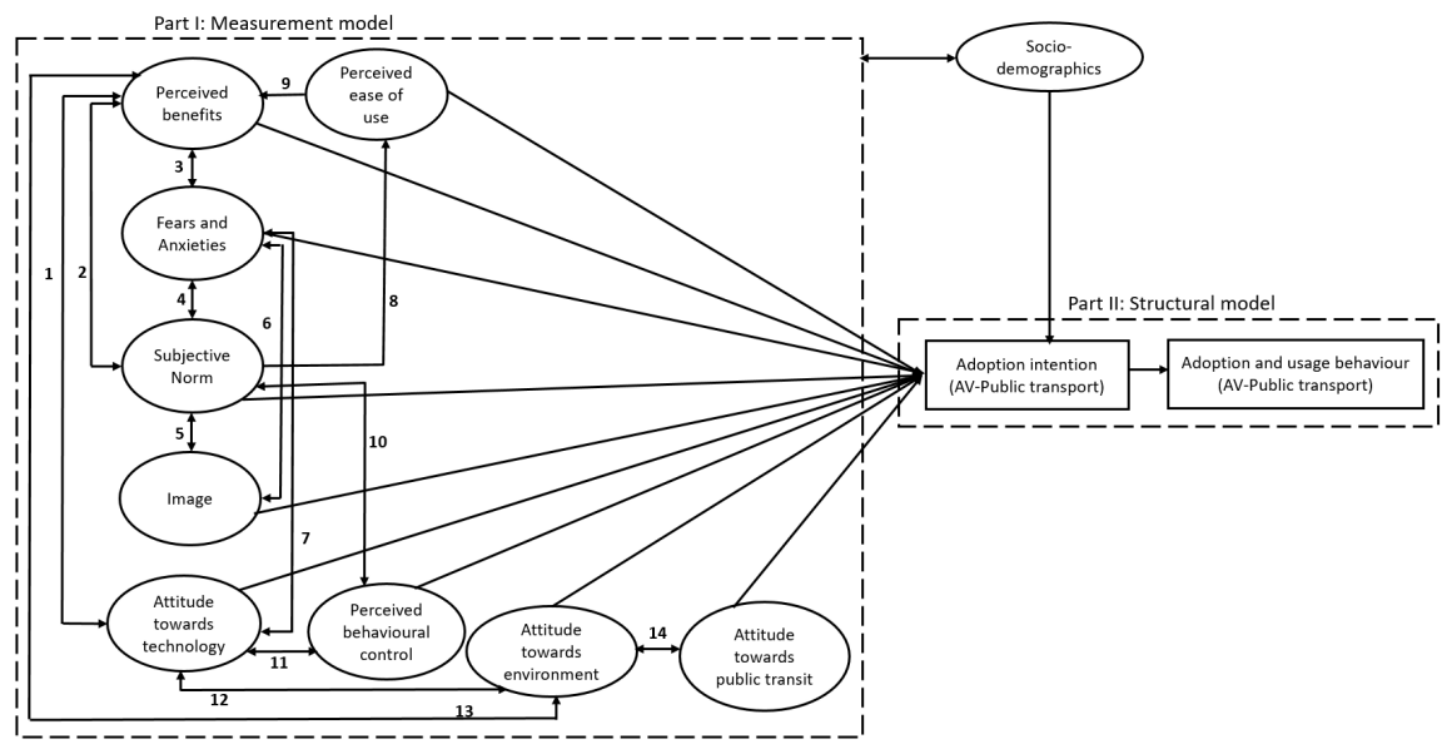

Fig 5: Conceptual model of AV public transport adoption behaviour (CM-3) 


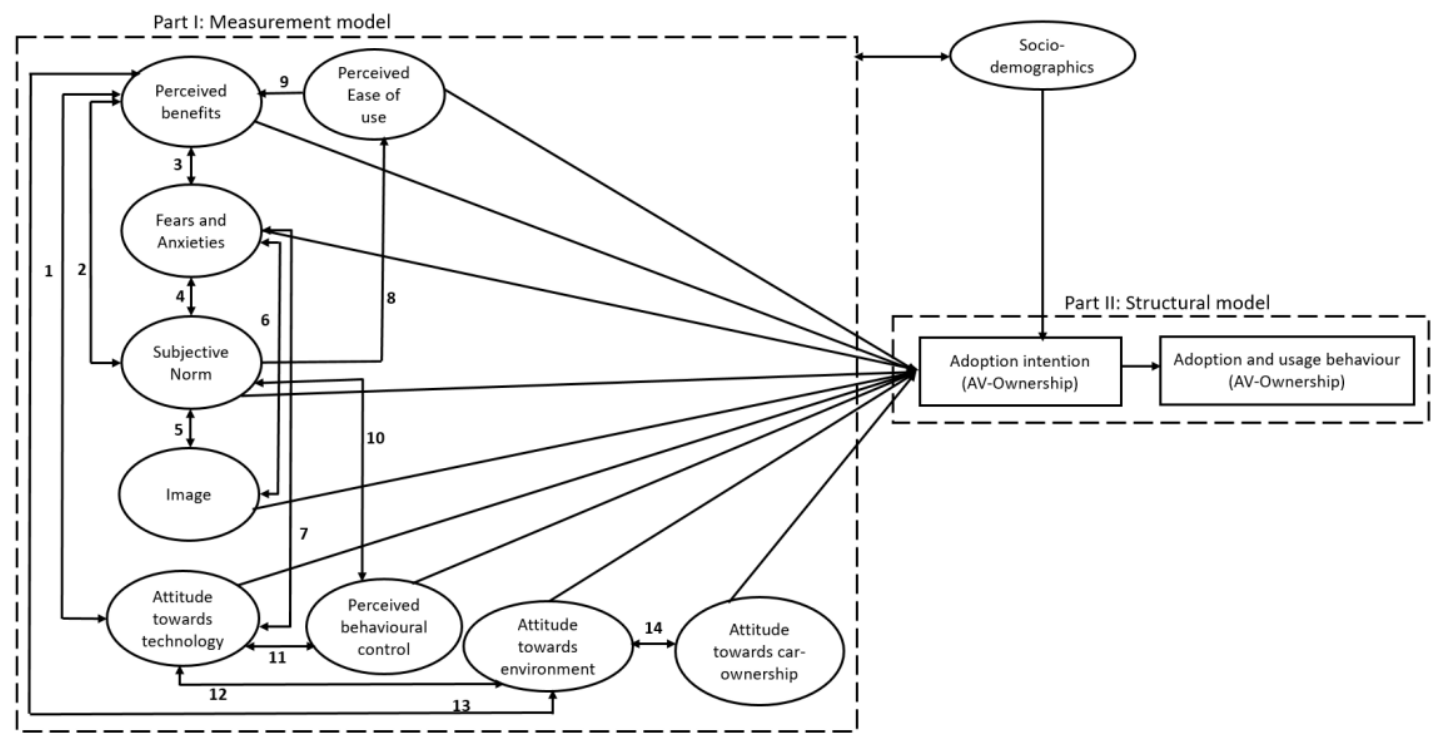

Fig 6: Conceptual model of AV-Ownership adoption behaviour (CM-4)

As mentioned in the introduction, the primary objectives of this paper are to assemble theorygrounded conceptual frameworks, and to test whether or not the hypothesized relationships among latent variables represented in Part-I of the conceptual models are indeed supported by empirical data. In the next section, we present the methodology employed to realize the latter objective, which involved questionnaire design, data collection and statistical modelling techniques.

\section{Methodology}

\subsection{Questionnaire design}

In deploying the conceptual models presented in the previous section, we identified relevant indicator items for each of the latent behavioural variables represented in the frameworks. The indicator items were then formulated to elicit responses from participants of the study on a 7-point Likert Scale. The precise wording of the questionnaire items and corresponding Likert Scale labels are presented later in section $\mathbf{5}$.

The survey elicited basic background socio-demographic information, including age, gender, income levels of educational attainment from the respondents. The response items in the questionnaire, which reflect the behavioural concepts we deployed, were presented to the respondents in themes, in accordance with the latent variables identified in the conceptual models. Preambles explaining to our respondents the meanings of key concepts and providing clear instructions to assist them in filling the survey, were provided in relevant sections of the questionnaire. For example, we explained the concept of autonomous/driverless cars as: " $a$ new technology that will enable cars, using advance sensing and communication technology, to take over safety-critical control functions. Fully-autonomous vehicles are expected to be able to drive under all road conditions without a human driver". Following this definition, all the response items covering perceived benefits and ease of use of $A V s$, perceived safety risks, subjective norm, image and perceived behavioural control, were presented to be evaluated 
by the respondents on a 7-point Likert Scale. The response items for perceived benefits and safety risks of AVs were adapted largely from initial exploratory surveys presented in Bansaal et al., (2016) and Litman (2017).

Another key concept in the survey that needed explaining to the respondents was the concept of collaborative consumption. This was explained to them as "a form of consumption where you don't have to own an asset or product. Instead, you and others in your community can book and use the product only when you need to do so. After using it, the product(s) must be returned for others to use". We followed this broad definition with specific examples of products/assets and services that fall under collaborative consumption or sharing, including bike-sharing, car-sharing, peer-to-peer accommodation-sharing, food-sharing, and garden sharing. The response items included in the questionnaire to capture people's attitude towards collaborative consumption were adapted from the work of Hamari and Colleagues (2016).

Finally, response items covering relevant attitudinal variables represented in the conceptual models, namely attitude towards technology, the environment, car ownership and public transit, were also included in the survey. The environmental attitudes sub-scale items presented to the respondents were adapted from the Environmental Attitudes Inventory (EAI) framework developed by Milfont and Duckitt (2010).

\subsection{Data Collection}

The data collection involved a two-step survey process. Firstly, we administered a pilot survey online to a convenience sample of 50 adult individuals. The purpose of this survey was twofold. First, the pilot survey allowed us to test the clarity of the questionnaire items, and to obtain a reasonable number of indicators items based on feedback we received from the respondents. Using the results of the pilot survey, we assessed the overall scale and sub-scale consistency and reliability of the questionnaire items by computing Cronbach's Alpha reliability coefficient. By assessing the relative contributions of each response item to overall and sub-scale reliabilities, we were able to eliminate the items that reduced reliability measures. Following this methodology, we reduced the 99 response items in the pilot survey questionnaire to 54 items in the final survey questionnaire that was ultimately administered to a random sample of respondents.

We administered the finalized survey questionnaire to a random sample population of adults living in the Greater Dublin Area of the Republic of Ireland. The survey was distributed via a combination of outlets, including printed leaflets with scannable QR-codes and questionnaire URL distributed by field assistants; emails sent to students and staff of all major universities in Dublin; and links shared on social media networks including Twitter and Facebook. The survey attracted a total of 507 respondents. 


\subsection{Specification and validation of measurement models}

Since our objective is to test whether or not the hypothesized relationships in Part-I of the four conceptual models presented in section 3 are supported by the survey data, we specified four measurement models using Confirmatory Factor Analysis (CFA). We evaluate model fit to ascertain the extent to which each of the hypothetical model's relationships are supported by the data, using model identification indices including: the Chi-square statistic $\left(\chi^{2}\right)$ and Normed Chi-square ( $\chi^{2} / \mathrm{df}$ ); Normed Fit Index (NFI); Comparative Fit Index (CFI); Tucker-Lewis Index (TLI); Incremental fit index (IFI); and Root Mean Square Error of Approximation (RMSEA). NFI, CFI, TLI and IFI values $\geq 0.90$ indicate acceptable model fit, while RMSEA value of $0.01,0.05$, and 0.08 indicate excellent, good, and mediocre fit, respectively (see Kline, 2015).

We further test overall scale and sub-scale item reliability and consistency by computing Cronbach's Alpha reliability coefficient $(\alpha)$. The coefficient ranges between 0 and 1 , and the closer it is to 1, the greater the internal consistency of the items in the scale (Gliem and Gliem, 2003). We establish convergent validity by examining factor loadings for the indicators of each of the latent variables, and by computing the Average Variance Explained (AVE)-the amount of variance that a latent variable explains in its indicator variables relative to the overall variance of its indicators. The minimum acceptable factor loadings is 0.5 (Hair et al., 2006) while convergent validity is established if AVE > 0.5 (Henseler et al., 2015). To establish discriminant validity, we calculate Maximum Shared Variance (MSV) by squaring the correlations of any two related latent variables. Discriminant validity is achieved where MSV $<$ AVE of any set of correlated latent variables (see Henseler et al., 2015; CamPerceivedbenefits-composite II and Fiske, 1959). The CFA analyses were performed using AMOS 21 software in SPSS.

\section{Results}

\subsection{Background characteristics of respondents}

Summary statistics on the socio-demographic and current travel characteristics of the study respondents are presented in Table 1. Females constituted $57 \%$ of the sample while $2 \%$ of the sample preferred not to indicate their gender. The survey respondents were aged between 18 and 82 years, with the average age being 33 years (SD $=15.350)$, compared to the average age of 37 years in the Republic of Ireland. In terms of age-groups, the proportion of the study respondents who fall within the age categories of 25-44 years (28\%) and 45-64 years (26\%) closely mirrors the national-level distribution of $29 \%$ and $24 \%$ respectively. In our sample, however, there are more younger people aged between 18 and 24 years (43\%) and fewer people aged 65 years and above (3\%) than in the national population.

The data on work/school travel mode choice shows that whereas nearly half $(49 \%)$ of the respondents use public transport, $22 \%$ and $29 \%$ use the private car and non-motorized modes of transport (i.e. bicycling and walking), respectively. Whereas less than $1 \%$ of the respondents currently use car-sharing services as their main work/school travel mode, a good 
number of them (47\%) indicated that they have participated in other collaborative consumption schemes, such as bike-sharing, food-sharing, accommodation-sharing and peerto-peer music sharing. Nearly a quarter of the total sample indicated that they were registered with and actively participated in one or more of the aforementioned collaborative consumption schemes.

Table 1: Background characteristics of the survey respondents

\begin{tabular}{|c|c|c|}
\hline & Variable & Distribution \\
\hline Gender & Female: Male: Prefer not to say & 57\%: $41 \%: 2 \%$ \\
\hline \multirow[t]{4}{*}{ Age-groups } & $18-24$ & $43 \%$ \\
\hline & $25-44$ & $28 \%$ \\
\hline & $45-64$ & $26 \%$ \\
\hline & $65-84$ & $3 \%$ \\
\hline \multirow[t]{5}{*}{ Education } & Primary school & $1 \%$ \\
\hline & Secondary/High school & $20 \%$ \\
\hline & Bachelors (enrolled) & $27 \%$ \\
\hline & Bachelors (completed). & $21 \%$ \\
\hline & Graduate (Master's or higher) & $31 \%$ \\
\hline \multirow[t]{7}{*}{ Ethnicity } & White Irish & $76 \%$ \\
\hline & Irish Travellers & $0.4 \%$ \\
\hline & Other White & $18 \%$ \\
\hline & Black Irish or Black African & $1.6 \%$ \\
\hline & Chinese & $0.6 \%$ \\
\hline & Other Asian & $2 \%$ \\
\hline & Others & $1.5 \%$ \\
\hline \multirow[t]{6}{*}{ Employment } & Full-time employment & $39 \%$ \\
\hline & Home-maker & $3 \%$ \\
\hline & Part-time employment & $18 \%$ \\
\hline & Retired & $3 \%$ \\
\hline & Student & $35 \%$ \\
\hline & Unemployed, actively looking for work & $2 \%$ \\
\hline \multirow[t]{6}{*}{ Income€ $(n=491)$} & $<20,000$ & $20 \%$ \\
\hline & $20,000-40,000$ & $8 \%$ \\
\hline & $41,000-60,000$ & $15 \%$ \\
\hline & $61,000-80,000$ & $13 \%$ \\
\hline & $81,000-100,000$ & $11 \%$ \\
\hline & $>100,000$ & $31 \%$ \\
\hline Car-ownership & Households owning car(s) & $81 \%$ \\
\hline Driver's license & Yes: No & $64 \%: 36 \%$ \\
\hline \multicolumn{3}{|l|}{ Travel mode choice (work/school; $n=496$ ) } \\
\hline & Private-car & $22 \%$ \\
\hline & Public transport-Bus & $24 \%$ \\
\hline & Public transport-Luas (Tram) & $23 \%$ \\
\hline & Car-sharing service & $0.4 \%$ \\
\hline & Motorcycle & $0.4 \%$ \\
\hline & Bicycle & $14 \%$ \\
\hline & Walking & $15 \%$ \\
\hline & Other & $0.3 \%$ \\
\hline Participated in collaborative consumption? & Yes: no: not sure & 47\%:43\%:10\% \\
\hline Sharing-club membership? & Yes: no & $23 \%: 77 \%$ \\
\hline Disability & Yes: No: Rather not say & $2 \%: 95 \%: 3 \%$ \\
\hline
\end{tabular}




\subsection{Specification of a measurement model based on the basic conceptual model of AV user adoption behaviour (CM-1)}

The first measurement model, hereafter referred to as measurement model-1, is based on the basic conceptual model of AV user adoption behaviour (CM-1) presented earlier in section 3 (see Fig 3). As previously stated, while CM-1 is intended for application in studies seeking to understand and predict the behavioural determinants of $\mathrm{AV}$ adoption intentions, the objective in the current paper is to test whether or not the empirical data supports the pairs of hypothesized relationships represented in the measurement model part of the framework (see Fig 3).

Descriptive summary of the survey data used in the CFA in measurement model-1, grouped as latent variables and their corresponding indicator items, is presented in Table 2. Cronbach's Alpha reliability coefficients indicate very good internal consistency and reliability of the overall item scale and sub-scales.

Table 2: Latent variables, indicator items and descriptive summary of study participants' responses

\begin{tabular}{|c|c|c|c|c|c|}
\hline \multirow[t]{2}{*}{ Items $^{1}$} & \multicolumn{5}{|c|}{ Scale $^{2}$} \\
\hline & 1 & 2 & 3 & 4 & 5 \\
\hline \multicolumn{6}{|l|}{ Affective attitude towards AVs $(\alpha=0.831)$} \\
\hline Driverless cars are a good idea & 11 & 18 & 17 & 28 & 26 \\
\hline Driverless cars are an exciting prospect & 8 & 13 & 9 & 32 & 37 \\
\hline \multicolumn{6}{|l|}{ Perceived Benefits of AVs- Instrumental utility ${ }^{34}(\alpha=0.906)$} \\
\hline *Driverless cars will reduce crashes & 23 & 11 & 12 & 20 & 34 \\
\hline *Driverless cars will save lives & 22 & 9 & 15 & 19 & 34 \\
\hline *Driverless cars will reduce traffic congestion & 26 & 14 & 16 & 16 & 29 \\
\hline *Driverless cars will lower vehicle emissions & 21 & 10 & 20 & 21 & 27 \\
\hline *Driverless cars will perform as well as conventional vehicles & 16 & 12 & 23 & 20 & 29 \\
\hline Driverless cars would reduce the stress of driving & 12 & 19 & 13 & 29 & 27 \\
\hline Driverless cars would be reliable & 12 & 20 & 13 & 29 & 27 \\
\hline Traveling in a driverless car would be comfortable & 9 & 16 & 17 & 31 & 26 \\
\hline Driverless cars would bring freedom in traveling around & 13 & 17 & 20 & 29 & 21 \\
\hline \multicolumn{6}{|l|}{ Perceived Benefits of AVs- On-board activities ${ }^{5} \quad(\alpha=0.902)$} \\
\hline Traveling in a driverless car would enable me to look out the window and enjoy the scenes outside & 11 & 12 & 15 & 32 & 32 \\
\hline Traveling in a driverless car would enable me to play my favourite games & 18 & 23 & 26 & 20 & 13 \\
\hline Traveling in a driverless car would enable me to communicate with my friends and colleagues & 12 & 15 & 21 & 32 & 19 \\
\hline Traveling in a driverless car would enable me to communicate with my family & 13 & 17 & 21 & 31 & 19 \\
\hline Traveling in a driverless car would enable me to get some work done & 14 & 21 & 18 & 27 & 21 \\
\hline \multicolumn{6}{|l|}{ Fears and Anxiety about AV technology-interaction with other road users ${ }^{6}{ }^{7}(\alpha=0.869)$} \\
\hline Driverless cars interacting with conventional vehicles & 29 & 40 & 15 & 12 & 4 \\
\hline Driverless cars interacting with pedestrians & 32 & 35 & 14 & 15 & 4 \\
\hline Driverless cars interacting with cyclists & 36 & 36 & 12 & 11 & 5 \\
\hline
\end{tabular}

\footnotetext{
${ }^{1}$ Overall scale reliability of all items, $\alpha=0.928$

${ }^{2}$ All items are presented on a five point Likert scale labelled as: 1 = strongly disagree; $2=$ disagree; $3=$ neutral; $4=$ agree; $5=$ strongly agree unless otherwise indicated in the relevant footnotes

3 * Item scale label: $1=$ very unlikely; $2=$ unlikely; $3=$ neutral; 4 = Likely; $5=$ Very likely

${ }^{4}$ Sub-scale items adapted from Bansaal et al., (2016) and Litman (2017)

${ }^{5}$ Sub-scale items adapted from Bansaal et al., 2016

${ }^{6}$ Item scale label: $1=$ very worried; $2=$ worried; $3=$ neither; $4=$ not worried; $5=$ not worried at all

${ }^{7}$ Sub-scale items adapted from Bansaal et al., 2016
} 
Fears and Anxiety about AV technology-automated system-related ${ }^{8}{ }^{9}(\alpha=0.736)$

Likelihood of equipment or system failure

Legal liability for owners and users

Hacking of the vehicle's computer systems

Image $(\alpha=\mathbf{0 . 9 6 4 )}$

Traveling in a driverless car, I would gain respect and recognition in my community

Traveling in a driverless car, I would gain respect and recognition among my friends and colleagues

Subjective Norm ( $\alpha=\mathbf{0 . 6 3 4})$

I will travel in a driverless car if my friends and colleagues do the same

Driverless vehicles will be the norm on our roads in the future

Attitude towards technology $(\alpha=\mathbf{0 . 8 8 7})$

I am excited about the possibilities offered by new technologies

I think advancement in technology is generally a positive thing

Attitude towards technology $(\alpha=\mathbf{0 . 6 2 8})$

I am sceptical about technology and its promises for a better future

I fear technology will completely replace humans and take over our jobs

$\begin{array}{lllll}30 & 41 & 13 & 12 & 4\end{array}$

$\begin{array}{lllll}24 & 42 & 18 & 13 & 3\end{array}$

$\begin{array}{lllll}33 & 37 & 16 & 12 & 2\end{array}$

Perceived Ease of Use

I believe it will be easy for me to travel in a driverless car

Perceived behavioural control

It would be up to me to travel in a driverless car or not

Notes $\alpha=$ Cronbach's Alpha reliability coefficient. Overall scale reliability of response items $(\alpha)=0.906$

Results of the survey show that affective attitude towards AVs is generally positive, as the majority of the respondents agree that driverless cars are generally a good idea (57\%) and that they are excited about the prospects of fully automated driving (72\%). Response items evaluated by the survey respondents regarding the potential benefits of $A V s$ reflect both their expected instrumental utility of commuting in an $\mathrm{AV}$ and the benefits of being able to perform additional on-board activities as AVs take over all safety-critical control functions from the human driver. Between $42 \%$ and $58 \%$ of the respondents agree that the potential utilitarian benefits of automated driving, including AVs reducing crashes and saving lives, providing reliable, flexible and comfortable travel, and reducing traffic congestion and environmental pollution, are likely. Similarly, more than half of the respondents are of the view that AVs would enable them to spend their travel times performing both recreational and productive activities. Regarding the perception of ease of use of AVs, we found that more individuals disagree that they would find it easy to use AVs (41\%) than those who agree (32\%) (See Table 2).

Public fears and concerns regarding AVs elicited through the survery are grouped under two broad categories. The first category reflect fears in relation to the potential risks associated with AVs interacting with other road users such as motorists, cyclists and pedestrains. The second category captures fears and anxieties that relate to the possibility of failure of automated systems of the vehicle through, for example, sudden techincal glitches in software or hardware or unathorised persons getting control by hacking into the vehicle's computer systems. Results of the survey show that between $64 \%$ and $71 \%$ of the survey respondents indicated either being worried or very worried about all the six potential safety and security risk factors associated with AVs that were presented to them.

\footnotetext{
${ }^{8}$ Item scale label: 1 = very worried; 2 = worried; $3=$ neither; $4=$ not worried; $5=$ not worried at all

${ }^{9}$ Sub-scale items adapted from Bansaal et al., 2016
} 
Moreover, with respect to the possible influence of external social factors on AV adoption from the respondents' point of view, we found that more than half of the respondents (i.e. $56 \%$ ) agree that AVs would become a diffused mode of transport and hence the norm on our roads in the near future. Opinions were, however, divided regarding the potential influence that significant others such friends and colleagues using AVs would have on the adoption decisions of the survey respondents. About $37 \%$ of our respondents agree that they would use driverless cars if their friends and colleagues did same, $26 \%$ were indifferent while the remaining $37 \%$ disagree. Also, more than half of the respondents (i.e. $53 \%$ ) agree that they would gain respect and recognition either from their friends and colleagues or in their community by using self-driving cars.

The last latent variable represented in measurement model-1 is individuals' attitude towards technology. From the survey, we found that the majority of the respondents agree that technological advancement is generally a positive thing (83\%) and that they are excited about the possibilities offered by new technologies (80\%). However, about $44 \%$ expressed scepticism about the notion that such advances would lead to a better future. Also, nearly half of the respondents agreed that advances in technology could result in job losses as automated systems replace humans in certain types of work.

The path-diagram of measurement model-1 (see Fig 7, appendix 1) shows the seven latent variables, their indicator items outlined above, and hypothesized relationships among them. We specify a higher order CFA in which overall Perceived Benefits of AVs (i.e. perceivedbenefits-composite) is represented as a function of three first-level latent variables. These are individuals' Affective Attitude towards AVs; perceived benefits that reflect the expected instrumental utility of commuting in an AV (i.e. perceived-benefits-1) and benefits that reflect the additional on-board activities that automated driving would enable commuters to perform (perceived-benefits-1). Covariance and correlations estimates for hypothesized associations, as well as regression weights for hypothesized direct effect relationships among latent variables in measurement model-1 are presented in Table 3.

The following pairs of hypothesized relationships are confirmed in measurement model-1:

- Public fears and anxiety regarding automating driving correlate positively with perceived benefits of AVs. This suggests that while genuine concerns exist in the population regarding $\mathrm{AV}$ system performance and $\mathrm{AVs}$ ' interaction with other road users, these do not necessarily diminish perceived benefits of AVs;

- Subjective norm (SN) and Image-belief that AV usage could be associated with enhanced reputation among colleagues and in one's community are positively correlated;

- Expectedly, more favourable attitudes towards technology (i.e. technology-attitude1) correlate negatively with expression of scepticism and negative attitudes towards technology (i.e. technology-attitude-2); 
- Pro-technology attitude also correlates positively with public fears and anxieties regarding automating driving, while the reverse is true between unfavourable attitude towards technology and public fears around AVs;

- There is a positive association between favourable attitudes towards technology in general and perception of the benefits of AVs in particular, while unfavourable attitudes with respect to the former correlate negatively with the latter;

- A negative association exists between unfavourable attitudes towards technology in general and perception of the benefits of AVs in particular;

- Subjective norm and public fears and anxiety regarding AVs are positively correlated. This suggests that respondents' belief that AVs will become the norm on public roads, and their desire to also use the technology as they see significant others do same, potentially attenuate their worries and concerns with respect to automating driving;

- Perceived behavioural control with respect to AV use and pro-technology attitudes are positively correlated.

- There is a positive association between perceived behavioural control with respect to AV use and subjective norm

- Education and pro-technology attitudes are positively correlated. This suggests that pro-technology attitudes increase among individuals with higher levels of educational attainment.

- Gender correlates negatively with overall perceived benefits of AVs (i.e. perceivedbenefits-composite). A cross-tabulation analysis of the survey data revealed that more females than males disagreed with all the response items we used to elicit their perception of the potential benefits of AVs. This suggests that perceived benefits of AVs decrease among females.

- Gender and negative attitude towards technology are positively correlated, suggesting that females are more likely to express scepticism about the overall benefits to society of technological advancement.

- Gender correlates negatively with both subjective norm and Image. This finding suggests that more females than males are less likely to agree that AVs becoming the norm, seeing significant others use AVs, and the reputational benefits of using AVs would influence their own adoption decisions.

- Gender and public fears and anxiety are negatively correlated. From the results of the survey, we identify that more females than males did agree that AVs could have potential negative safety and security impacts.

- Subjective norm directly predicts first-level indicators of perceived benefits of AVs (i.e. perceived-benefits-1 and perceived-benefits-1), and perceived ease of use (PEU) of automated driving technology;

- Individuals' perception of ease of use of driverless vehicles directly predicts affective attitude towards AVs and the other two measures of perceived benefits of AVs (i.e. perceived-benefits-1 and perceived-benefits-2). 
- Education predicts perceived ease of use, suggesting that as levels of education increases from basic level towards tertiary qualifications, individuals' belief that AVs would be easy to use increases.

- Education has a positive predictive effect on perceived-benefits of AVs (i.e. perceived-benefits-1)

- Age has a negative predictive effect on perceived-benefits of AVs (i.e. perceivedbenefits-2). This finding suggests that the expected benefits in the form of travel time use while in recreational and/or productive activities, decrease among older population.

Table 3: Correlations, covariance and regression weights of relationships among variables in measurement model-1

\begin{tabular}{|c|c|c|c|c|c|c|c|}
\hline & & & & & & & \\
\hline & & & & & & & \\
\hline $\begin{array}{l}\text { Fear-and-anxiety- } \\
\text { composite }\end{array}$ & $<-->$ & Technology-attitude-positive & 0.033 & 0.058 & 0.027 & 1.226 & 0.022 \\
\hline $\begin{array}{l}\text { Fear-and-anxiety- } \\
\text { composite }\end{array}$ & $<-->$ & $\begin{array}{l}\text { Perceived-benefits- } \\
\text { composite }\end{array}$ & 0.047 & 0.36 & 0.012 & 3.847 & $* * *$ \\
\hline $\begin{array}{l}\text { Fear-and-anxiety- } \\
\text { composite }\end{array}$ & $<-->$ & Image & 0.173 & 0.307 & 0.031 & 5.548 & $* * *$ \\
\hline Subjective norm & $<-->$ & Image & 0.238 & 0.446 & 0.029 & 8.293 & $* * *$ \\
\hline $\begin{array}{l}\text { Technology-attitude- } \\
\text { negative }\end{array}$ & $<-->$ & $\begin{array}{l}\text { Perceived-benefits- } \\
\text { composite }\end{array}$ & -0.022 & -0.17 & 0.009 & -2.366 & 0.018 \\
\hline $\begin{array}{l}\text { Technology-attitude- } \\
\text { positive }\end{array}$ & $<-->$ & $\begin{array}{l}\text { Perceived-benefits- } \\
\text { composite }\end{array}$ & 0.042 & 0.181 & 0.013 & 3.128 & 0.002 \\
\hline $\begin{array}{l}\text { Fear-and-anxiety- } \\
\text { composite }\end{array}$ & $<-->$ & $\begin{array}{l}\text { Technology-attitude- } \\
\text { negative }\end{array}$ & -0.065 & -0.201 & 0.021 & -3.025 & 0.002 \\
\hline $\begin{array}{l}\text { Technology-attitude- } \\
\text { positive }\end{array}$ & $<-->$ & $\begin{array}{l}\text { Technology-attitude- } \\
\text { negative }\end{array}$ & -0.065 & -0.114 & 0.033 & -1.995 & 0.046 \\
\hline Subjective norm & $<-->$ & $\begin{array}{l}\text { Perceived-benefits- } \\
\text { composite }\end{array}$ & 0.058 & 0.475 & 0.014 & 4.059 & $* * *$ \\
\hline $\begin{array}{l}\text { Fear-and-anxiety- } \\
\text { composite }\end{array}$ & $<-->$ & Subjective norm & 0.169 & 0.561 & 0.025 & 6.84 & $* * *$ \\
\hline $\begin{array}{l}\text { Perceived behavioural } \\
\text { control }\end{array}$ & $<-->$ & Technology-attitude-positive & 0.226 & 0.319 & 0.032 & 7.159 & $* * *$ \\
\hline $\begin{array}{l}\text { Perceived behavioural } \\
\text { control }\end{array}$ & $<-->$ & Subjective norm & 0.072 & 0.189 & 0.016 & 4.371 & $* * *$ \\
\hline Education & $<-->$ & Technology-attitude-positive & 0.116 & 0.101 & 0.051 & 2.282 & 0.022 \\
\hline Age & $<-->$ & $\begin{array}{l}\text { Technology-attitude- } \\
\text { negative }\end{array}$ & -1.024 & -0.116 & 0.501 & -2.041 & 0.041 \\
\hline Age & $<-->$ & Fear-and-anxiety-composite & -0.729 & -0.084 & 0.403 & -1.807 & 0.071 \\
\hline Gender & $<-->$ & $\begin{array}{l}\text { Perceived-benefits- } \\
\text { composite }\end{array}$ & -0.024 & -0.209 & 0.007 & -3.344 & $* * *$ \\
\hline Gender & $<-->$ & $\begin{array}{l}\text { Technology-attitude- } \\
\text { negative }\end{array}$ & 0.054 & 0.193 & 0.017 & 3.176 & 0.001 \\
\hline Gender & $<-->$ & Subjective norm & -0.044 & -0.17 & 0.013 & -3.318 & $* * *$ \\
\hline Gender & $<-->$ & Fear-and-anxiety-composite & -0.064 & -0.231 & 0.015 & -4.143 & $* * *$ \\
\hline Gender & $<-->$ & Image & -0.069 & -0.142 & 0.022 & -3.196 & 0.001 \\
\hline B. Direct Effects & & & & & & & \\
\hline Variables & & & B & b & SE & CR & $\mathbf{P}$ \\
\hline Perceived-benefits-2 & $<--$ & Subjective norm & 0.444 & 0.324 & 0.118 & 3.753 & $* * *$ \\
\hline $\begin{array}{l}\text { Perceived behavioural } \\
\text { control }\end{array}$ & $<-$ & Subjective norm & 1.215 & 0.741 & 0.1 & 12.137 & $* * *$ \\
\hline Perceived-benefits-1 & $<--$ & Subjective norm & 0.412 & 0.386 & 0.077 & 5.361 & $* * *$ \\
\hline Perceived-benefits-2 & $<-$ & $\begin{array}{l}\text { Perceived behavioural } \\
\text { control }\end{array}$ & 0.191 & 0.229 & 0.059 & 3.229 & 0.001 \\
\hline Affective attitude & $<--$ & $\begin{array}{l}\text { Perceived behavioural } \\
\text { control }\end{array}$ & 0.307 & 0.436 & 0.044 & 6.92 & $* * *$ \\
\hline
\end{tabular}




\begin{tabular}{|c|c|c|c|c|c|c|c|}
\hline Perceived-benefits-1 & $<--$ & $\begin{array}{l}\text { Perceived behavioural } \\
\text { control }\end{array}$ & 0.196 & 0.301 & 0.043 & 4.517 & $* * *$ \\
\hline $\begin{array}{l}\text { Perceived behavioural } \\
\text { control }\end{array}$ & $<-$ & Education & 0.068 & 0.09 & 0.026 & 2.616 & 0.009 \\
\hline Perceived-benefits-1 & $<--$ & Education & 0.028 & 0.056 & 0.012 & 2.229 & 0.026 \\
\hline Perceived-benefits-2 & $<--$ & Age & -0.003 & -0.069 & 0.002 & -1.985 & 0.047 \\
\hline
\end{tabular}

Notes: $\beta=$ Unstandardized regression estimates; $b=$ standardized regression estimates; $S E=$ standard error; $C R=$ critical

ratio; $\mathrm{P}=\mathrm{p}$-value; $* * * \mathrm{P}$-value $<0.01$

\subsection{Specification of a measurement model based on the conceptual model of AV- sharing adoption behaviour (CM-2)}

In the second measurement model, we test the pairs of hypothesized relationships specified in the conceptual model of AV-sharing adoption behaviour (CM-2). Measurement model-2 builds on measurement model-1. It therefore includes all the latent variables in measurement model-1, plus two latent variables measuring attitudes towards the environment and attitude towards collaborative consumption/sharing. As shown in Fig $\mathbf{8}$ and Fig $\mathbf{9}$, the majority of survey respondents indicated positive attitude towards collaborative consumption and the environment. For example, more than $70 \%$ of the respondents agreed that collaborative consumption is a positive thing and that participating in sharing schemes would bring about monetary and environmental sustainability benefits.

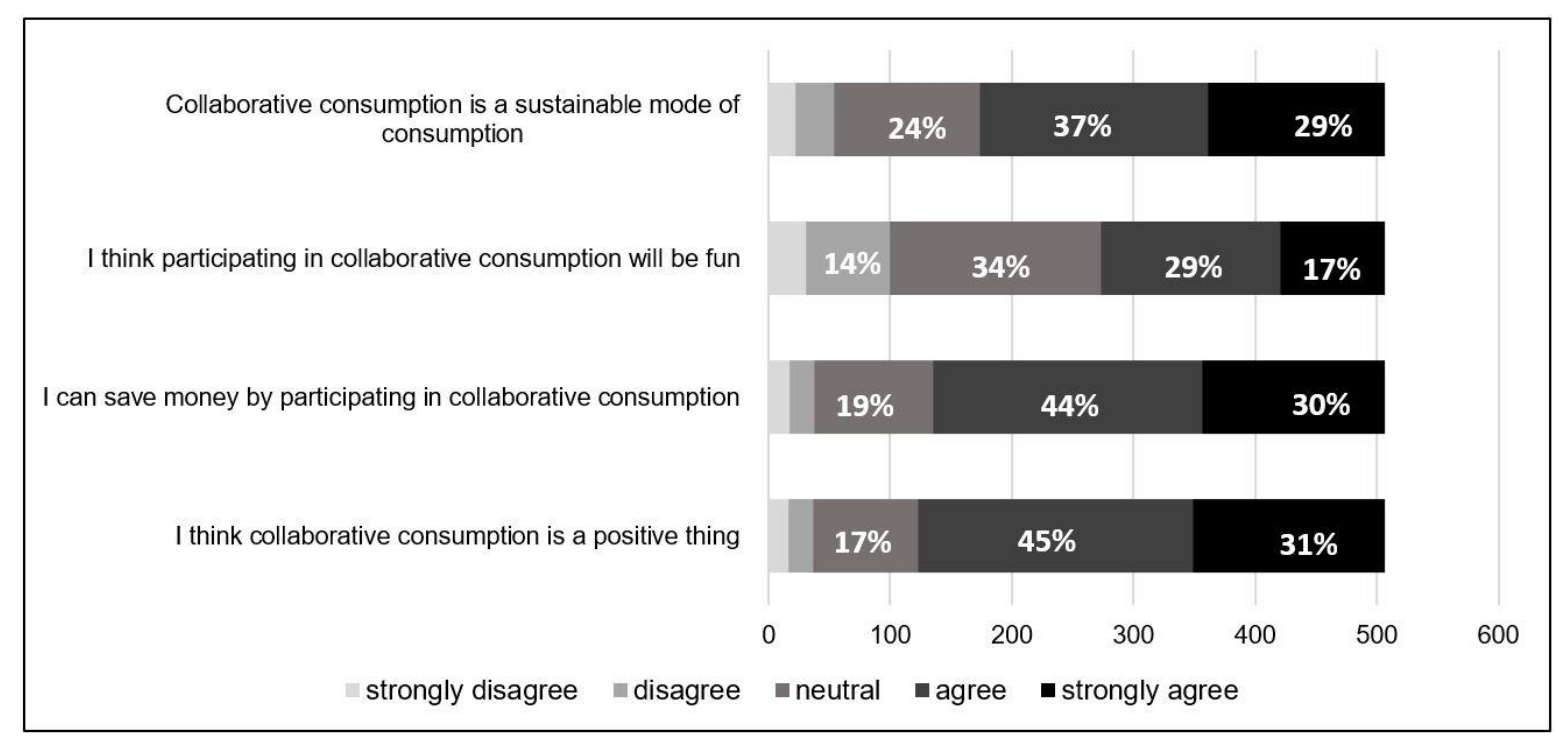

Fig 8: Summary of respondents' attitude towards collaborative consumption $(\alpha=0.880)$ 


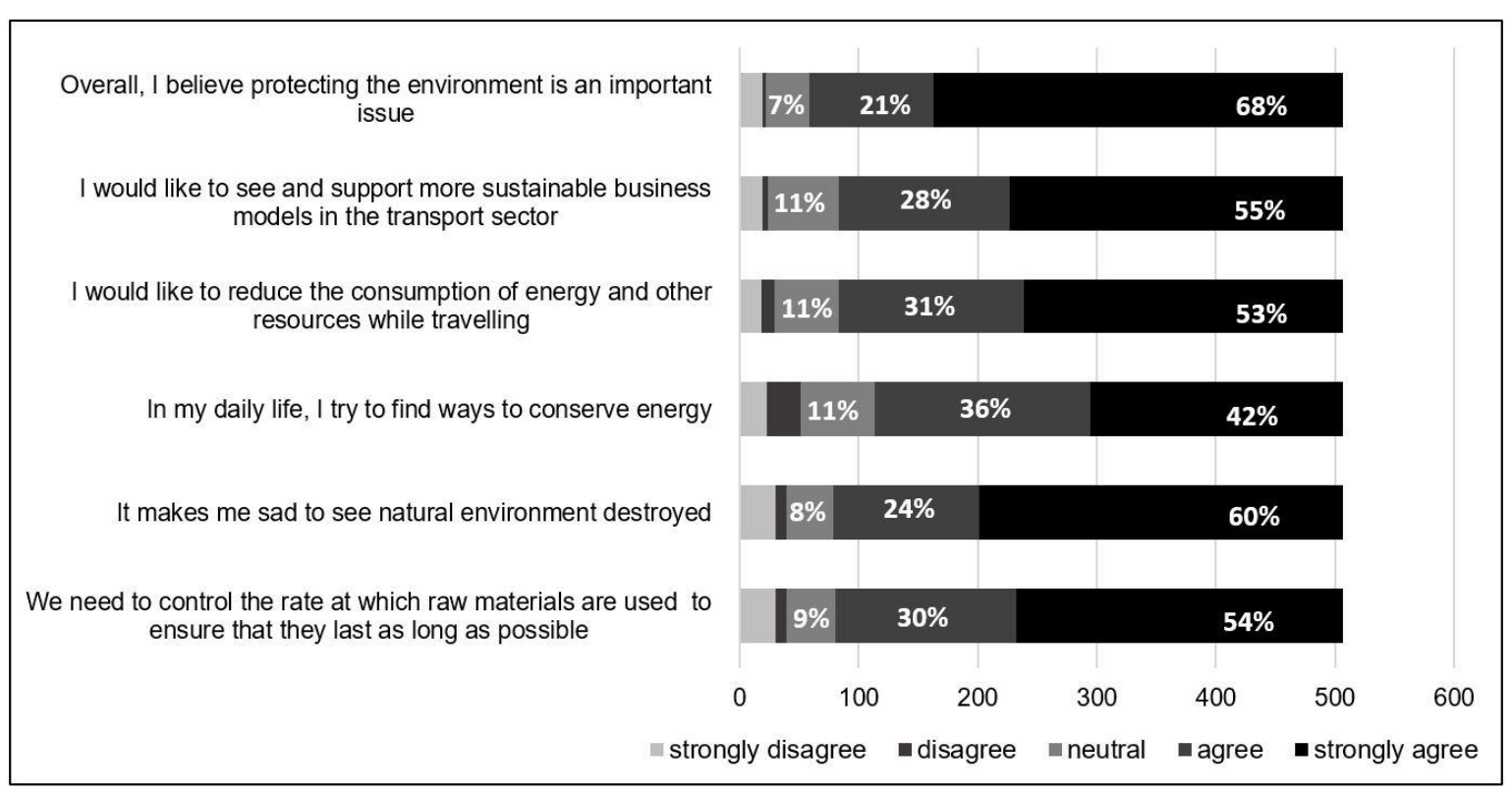

Fig 9: Summary of respondents' attitude towards the environment $(\alpha=0.939)$

Fig 10, appendix 1 shows the path-diagram of measurement model-2, while Table 4 presents a summary of the corresponding covariance and correlations estimates for hypothesized associations, as well as regression weights for hypothesized direct effect relationships among variables in the model. We confirm the following additional pairs of relationships among latent variables:

- Attitude towards collaborative consumption, which reflects expectations of the outcomes of participating in access-based/sharing consumption models such as carsharing, correlate positively with pro-environmental attitudes;

- Pro-technology attitude also correlates positively with attitude towards participation in technology-mediated access-based/sharing consumption models such as carsharing;

- Results of the model shows a positive association between pro-environmental attitudes and pro-technology attitudes;

- The composite measure of perceived benefits of AVs (i.e. perceived- benefits-1 + perceived-benefits-2) correlates positively with pro-environmental attitudes.

- Education and pro-environmental attitudes are positively correlated. This suggests that as individuals' levels of educational attainment increase from basic level towards tertiary qualifications, positive attitudes towards the environment increase.

- Positive association exists between pro-environmental attitude and gender. From the survey data, we found that more females than males agreed with each of response items measuring their attitudes towards the environment.

- Education and collaborative consumption attitudes are positively correlated.

- There is a positive association between collaborative consumption attitudes and gender. From the survey data, we found that more females than males agreed that participating in collaborative consumption would yield positive benefits. 
- Finally, age and collaborative consumption attitudes are negatively correlated, suggesting that younger individuals are more likely to agree that participating in collaborative consumption would bring positive benefits, while older people do not expect similar outcomes.

Table 4: Correlations, covariance and regression weights of relationships among variables in measurement model-2

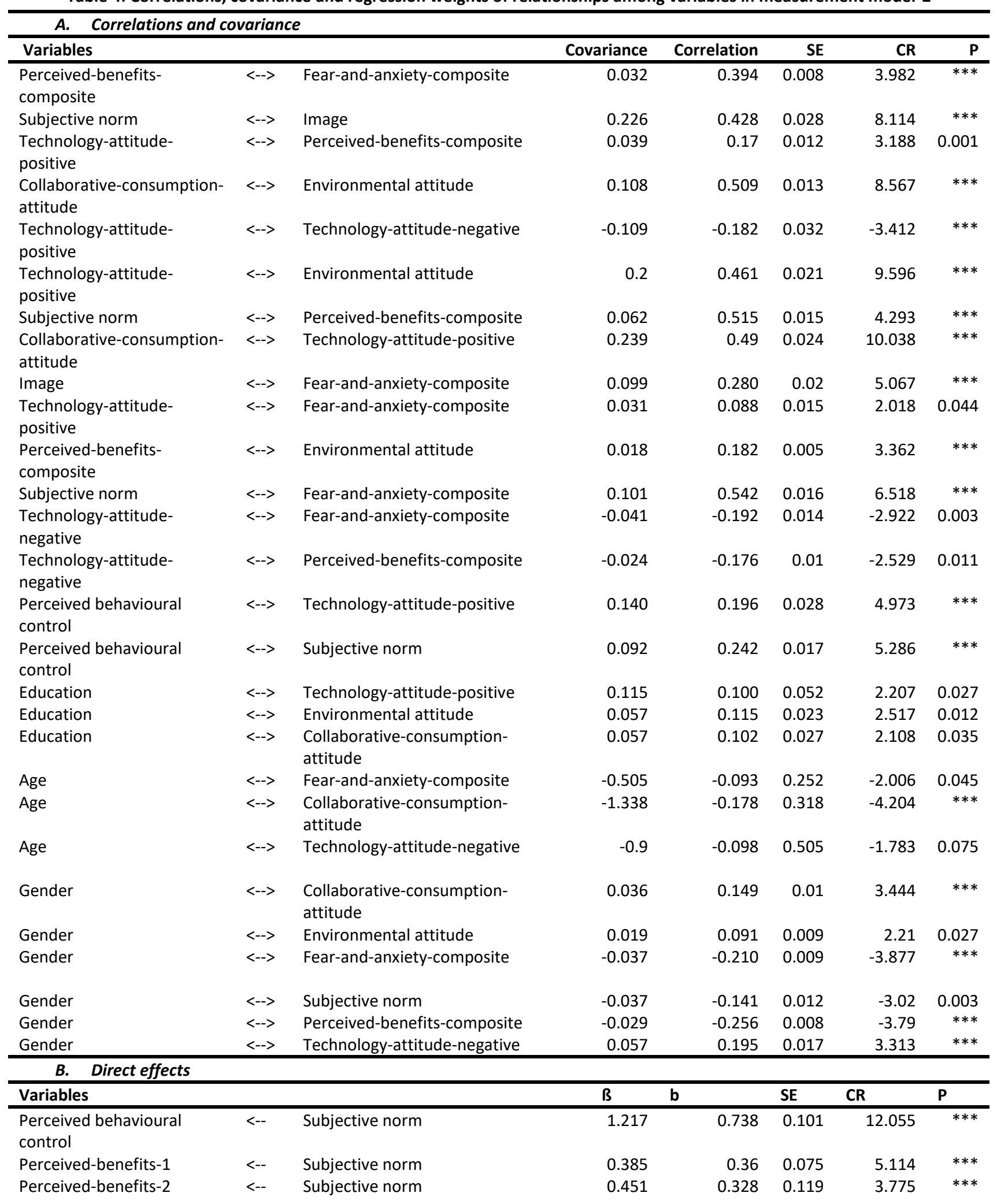


Perceived-benefits-2

Affective attitude

Perceived-benefits-1

Perceived behavioural

control

Perceived-benefits-1

Perceived-benefits-2

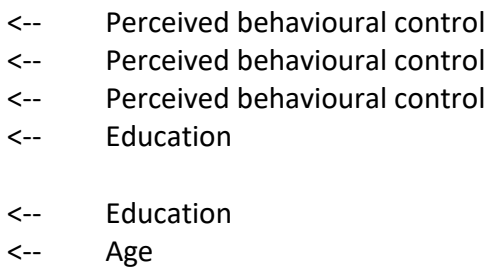

0.176
0.282
0.187
0.066

0.026
-0.003

0.211

0.402

0.288

0.088

0.059

0.043

0.043

0.026

$0.054 \quad 0.012$

$-0.071 \quad 0.002$
2.996

6.501

4.351

2.561

2.117

0.034

Notes: $\beta=$ Unstandardized regression estimates; $b=$ standardized regression estimates; $S E=$ standard error; $C R=$ critical ratio; $\mathrm{P}=\mathrm{p}$-value; $* * * \mathrm{P}$-value $<0.01$

\subsection{Specification of a measurement model based on the conceptual model of AV- public transport adoption behaviour (CM-3)}

As automated driving technology advances, researchers may be interested in knowing whether or not the public would use public transit services provided by AVs and the underlying behavioural factors. Measurement model-3, which is based on the conceptual model of AV-public transport adoption behaviour ( $\mathrm{CM}-3)$ tests the relationships among the latent variables which would be relevant in such research applications. As indicated previously, individuals' attitude towards public transit in general would influence whether or not they use public transport services provided by AVs. Consequently, we include in this model, a latent variable measuring attitudes towards public transit (see Fig 11), in addition to the relevant variables already captured in measurement model- 1 and measurement model-

2.

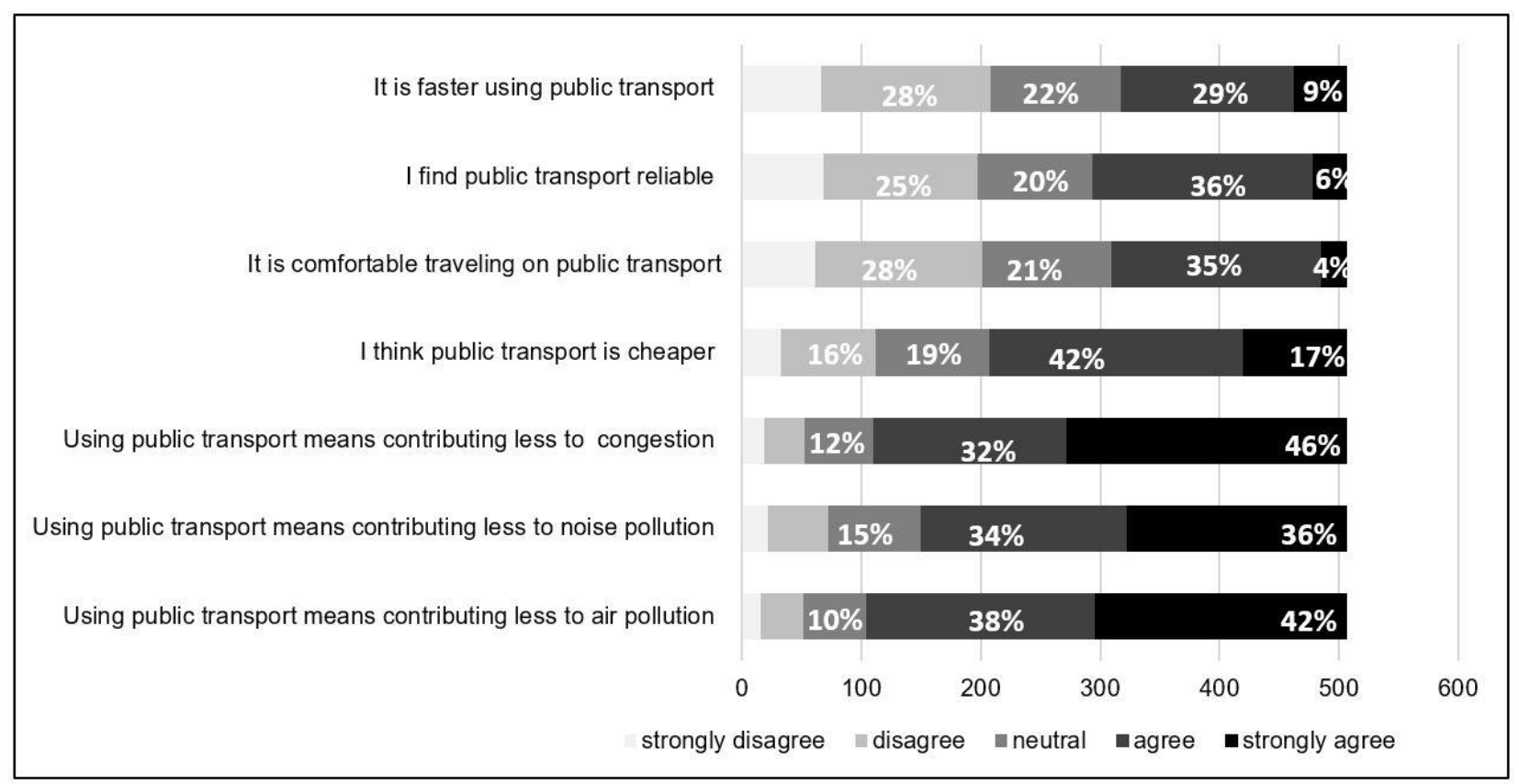

Fig 11: Summary of respondents' attitude towards public transit $(\alpha=0.823)$

In the path diagram (see Fig 12, appendix 1), public transit attitude is represented as a composite, higher-order variable derived from two first-level latent variables. These are public-transit-atttiude- 1 and public-transit-attitude-2, which reflect environmental benefits of mass transit and the instrumental utility aspects of using public transit, as perceived by individuals, respectively. Table 5 shows the covariance and correlation estimates for 
associations, and regression weights for direct effect relationships among latent variables specified in measurement model-3. In addition to the hypotheses, confirmed in the preceding measurement models, the following pairs of relationships are confirmed in measurement model-3:

- Both measures of pro-public transit attitudes (i.e. public-transit-attitude-1 and public-transit-attitude-2) are positively correlated;

- Pro-public transit attitudes are associated positively with pro-environmental attitudes;

- Composite measure of perceived benefits of AVs (i.e. Affective attitude towards AV + perceived-benefits-1+ perceived-benefits-1) correlates positively with pro-public transit attitudes.

- Age and pro-public transit attitude are negatively correlated. From the survey data, we found that, more younger people (i.e. individuals between the ages of 18 and mid30s) than older people agreed to all the response items measuring public transit attitudes.

Table 5: Correlations, covariance and regression weights of relationships among variables in measurement model-3

\begin{tabular}{|c|c|c|c|c|c|c|c|}
\hline Variables & & & Covariance & Correlation & SE & CR & $\mathbf{P}$ \\
\hline $\begin{array}{l}\text { Perceived-benefits- } \\
\text { composite }\end{array}$ & $<-->$ & Fear-and-anxiety-composite & 0.035 & 0.396 & 0.008 & 4.157 & $* * *$ \\
\hline $\begin{array}{l}\text { Technology-attitude- } \\
\text { positive }\end{array}$ & $<->$ & Environmental attitude & 0.161 & 0.381 & 0.019 & 8.298 & $* * *$ \\
\hline Public-transit-attitude & $<-->$ & Perceived-benefits-composite & 0.016 & 0.127 & 0.007 & 2.184 & 0.029 \\
\hline $\begin{array}{l}\text { Technology-attitude- } \\
\text { negative }\end{array}$ & $<-->$ & Perceived-benefits-composite & -0.028 & -0.193 & 0.01 & -2.73 & 0.006 \\
\hline Subjective norm & $<-->$ & Image & 0.229 & 0.431 & 0.028 & 8.114 & $* * *$ \\
\hline Public-transit-attitude & $<-->$ & Environmental attitude & 0.076 & 0.353 & 0.012 & 6.383 & $* * *$ \\
\hline Subjective norm & $<->$ & Perceived-benefits-composite & 0.065 & 0.489 & 0.015 & 4.326 & $* * *$ \\
\hline $\begin{array}{l}\text { Technology-attitude- } \\
\text { positive }\end{array}$ & $<-->$ & Technology-attitude-negative & -0.09 & -0.153 & 0.033 & -2.759 & 0.006 \\
\hline $\begin{array}{l}\text { Technology-attitude- } \\
\text { negative }\end{array}$ & $<-->$ & Fear-and-anxiety-composite & -0.043 & -0.204 & 0.014 & -3.06 & 0.002 \\
\hline Subjective norm & $<-->$ & Fear-and-anxiety-composite & 0.102 & 0.54 & 0.016 & 6.483 & $* * *$ \\
\hline $\begin{array}{l}\text { Technology-attitude- } \\
\text { positive }\end{array}$ & $<-->$ & Fear-and-anxiety-composite & 0.026 & 0.074 & 0.016 & 1.599 & 0.11 \\
\hline Image & $<-->$ & Fear-and-anxiety-composite & 0.097 & 0.274 & 0.02 & 4.955 & $* * *$ \\
\hline $\begin{array}{l}\text { Technology-attitude- } \\
\text { positive }\end{array}$ & $<-->$ & Perceived-benefits-composite & 0.045 & 0.179 & 0.014 & 3.188 & 0.001 \\
\hline $\begin{array}{l}\text { Perceived-benefits- } \\
\text { composite }\end{array}$ & $<-->$ & Environmental attitude & 0.023 & 0.219 & 0.006 & 3.635 & $* * *$ \\
\hline $\begin{array}{l}\text { Perceived behavioural } \\
\text { control }\end{array}$ & $<-->$ & Subjective norm & 0.087 & 0.229 & 0.017 & 5.051 & $* * *$ \\
\hline Gender & $<->$ & Technology-attitude-negative & 0.058 & 0.201 & 0.017 & 3.345 & $* * *$ \\
\hline $\begin{array}{l}\text { Perceived behavioural } \\
\text { control }\end{array}$ & $<-->$ & Technology-attitude-positive & 0.173 & 0.243 & 0.03 & 5.756 & $* * *$ \\
\hline Education & $<-->$ & Technology-attitude-positive & 0.073 & 0.064 & 0.048 & 1.515 & 0.13 \\
\hline Age & $<-->$ & Perceived-benefits-composite & -0.115 & -0.03 & 0.182 & -0.636 & 0.525 \\
\hline Age & $<-->$ & Environmental attitude & -0.126 & -0.019 & 0.279 & -0.453 & 0.651 \\
\hline Age & $<-->$ & Public-transit-attitude & -0.877 & -0.113 & 0.405 & -2.167 & 0.03 \\
\hline Age & $<-->$ & Technology-attitude-negative & -1.05 & -0.116 & 0.508 & -2.067 & 0.039 \\
\hline Age & $<-->$ & Technology-attitude-negative & -1.05 & -0.116 & 0.508 & -2.067 & 0.039 \\
\hline
\end{tabular}




\begin{tabular}{|c|c|c|c|c|c|c|c|}
\hline Gender & $<-->$ & Environmental attitude & 0.017 & 0.082 & 0.008 & 2.036 & 0.042 \\
\hline Gender & $<-->$ & Subjective norm & -0.031 & -0.12 & 0.012 & -2.564 & 0.01 \\
\hline Gender & $<-->$ & Perceived-benefits-composite & -0.03 & -0.242 & 0.008 & -3.803 & $* * *$ \\
\hline Gender & $<->$ & Fear-and-anxiety-composite & -0.034 & -0.194 & 0.009 & -3.582 & $* * *$ \\
\hline \multicolumn{8}{|l|}{ B. Direct effects } \\
\hline Variables & & & ß & b & SE & CR & $\mathbf{P}$ \\
\hline $\begin{array}{l}\text { Perceived behavioural } \\
\text { control }\end{array}$ & $<-$ & Subjective norm & 1.216 & 0.741 & 0.101 & 12.085 & $* * *$ \\
\hline Perceived-benefits-2 & $<--$ & Perceived behavioural control & 0.19 & 0.23 & 0.059 & 3.208 & 0.001 \\
\hline Affective attitude & $<--$ & Perceived behavioural control & 0.282 & 0.409 & 0.043 & 6.615 & $* * *$ \\
\hline Perceived-benefits-1 & $<--$ & Perceived behavioural control & 0.186 & 0.291 & 0.043 & 4.314 & $* * *$ \\
\hline Perceived-benefits-1 & $<--$ & Subjective norm & 0.364 & 0.347 & 0.075 & 4.876 & $* * *$ \\
\hline Perceived-benefits- 2 & $<--$ & Subjective norm & 0.387 & 0.285 & 0.118 & 3.289 & 0.001 \\
\hline $\begin{array}{l}\text { Perceived behavioural } \\
\text { control }\end{array}$ & $<--$ & Education & 0.071 & 0.094 & 0.026 & 2.733 & 0.006 \\
\hline Perceived-benefits-1 & $<--$ & Education & 0.027 & 0.055 & 0.012 & 2.152 & 0.031 \\
\hline Perceived-benefits- 2 & $<--$ & Age & -0.003 & -0.066 & 0.002 & -1.865 & 0.062 \\
\hline
\end{tabular}

Notes: $\beta=$ Unstandardized regression estimates; $b=$ standardized regression estimates; $\mathrm{SE}=$ standard error; $\mathrm{CR}=\mathrm{critical}$ ratio; $\mathrm{P}=\mathrm{p}$-value; $* * * \mathrm{P}$-value $<0.01$

\subsection{Specification of a measurement model based on the conceptual model of AV- Ownership adoption behaviour (CM-4)}

In the final measurement model (i.e. measurement model-4), we test the pairs of relationships specified in the conceptual model of AV-Ownership adoption behaviour (CM-4). As previously indicated, this model would provide the foundation for studies where the objective is to identify the behavioural determinants of whether or not individuals would prefer to own AVs. In view of this, measurement model-4 maintains all latent variables in measurement model-2, except for the collaborative consumption attitude variable, which we replace with individuals' attitude toward car ownership. Descriptive summary of individual's responses to the items measuring their attitudes towards car ownership/use is presented are presented in Fig 13.

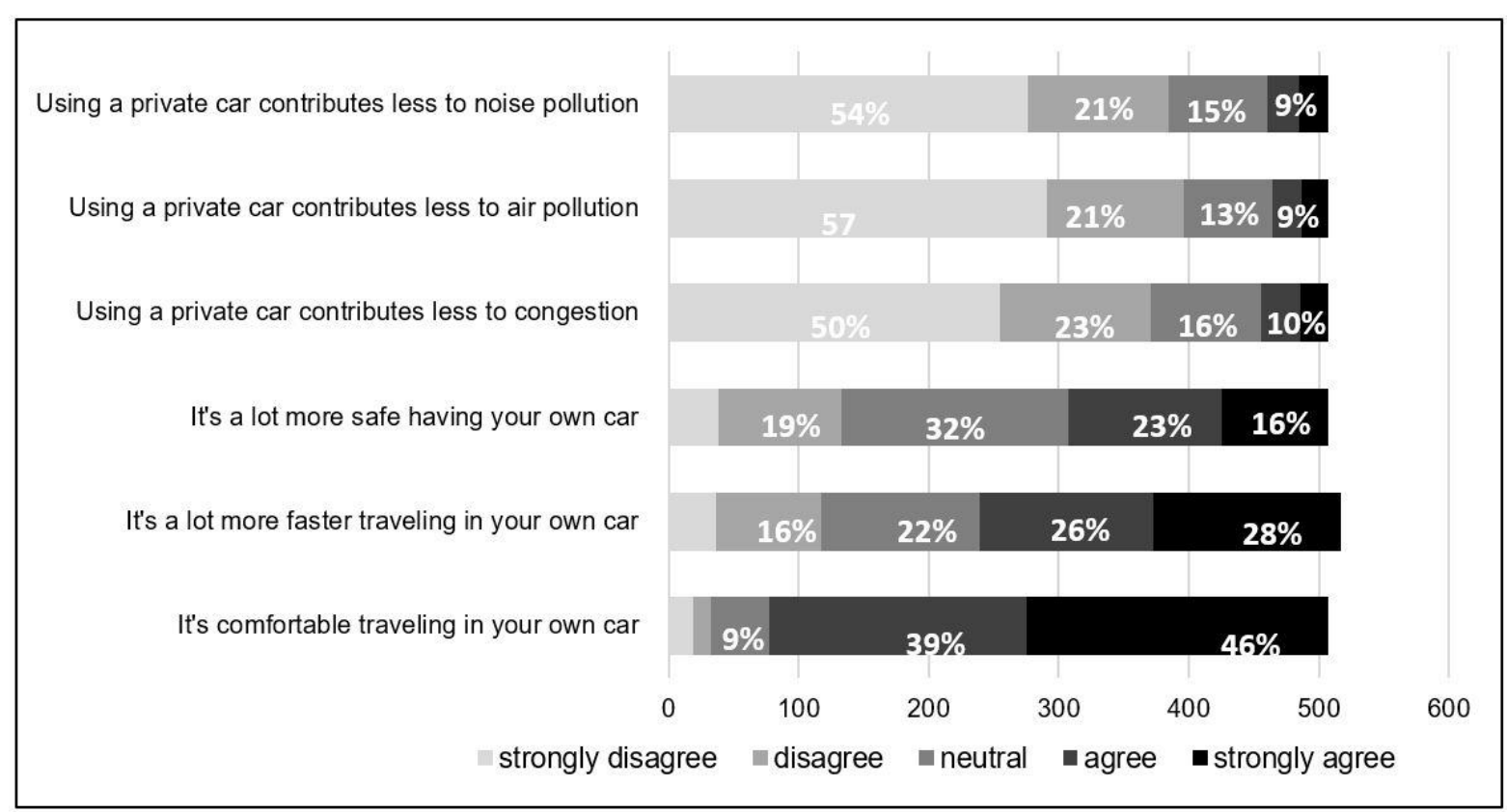

Fig 13: Summary of respondents' attitude towards car ownership/use $(\alpha=0.763)$ 
In measurement model-4 (see Fig 14, appendix 1), we confirm the following pairs of relationships among the study variables:

- Attitudes towards instrumental benefits of car-ownership (Car-ownership-benefits-

1) correlate positively with pro-environmental attitudes;

- A pro-technology attitude correlates positively with attitudes towards instrumental benefits of car-ownership;

- The perception of the environmental-related impact of car-ownership, including contributing to congestion, noise and air pollution, is negatively associated with proenvironmental attitudes.

- Education and car-ownership attitudes are negatively correlated, suggesting that in our sample, highly educated individuals tend not to favour car-ownership and use.

- We found no statistically significant relationship between attitude towards carownership and use and perceived benefits of AVs.

Table 6 shows the covariance and correlation estimates for associations, and regression weights for direct effect relationships among latent variables specified in measurement model-3

Table 6: Correlations, covariance and regression weights of relationships among variables in measurement model-1

\begin{tabular}{|c|c|c|c|c|c|c|c|}
\hline & & & & & $\mathrm{JL}$ & $2 \pi$ & \\
\hline Technology-attitude-positive & $<-->$ & Environmental attitude & 0.199 & 0.458 & 0.021 & 9.523 & $* * *$ \\
\hline Subjective norm & $<-->$ & Image & 0.229 & 0.43 & 0.028 & 8.113 & $* * *$ \\
\hline Car-ownership-attitude-2 & $<->$ & Car-ownership-attitude-1 & 0.060 & 0.251 & 0.017 & 3.63 & $* * *$ \\
\hline Technology-attitude-negative & $<-->$ & $\begin{array}{l}\text { Perceived-benefits- } \\
\text { composite }\end{array}$ & -0.029 & -0.200 & 0.01 & -2.817 & 0.005 \\
\hline Technology-attitude-positive & $<->$ & Car-ownership-attitude-1 & 0.137 & 0.242 & 0.03 & 4.623 & $* * *$ \\
\hline Technology-attitude-positive & $<->$ & $\begin{array}{l}\text { Perceived-benefits- } \\
\text { composite }\end{array}$ & 0.051 & 0.201 & 0.014 & 3.525 & $* * *$ \\
\hline $\begin{array}{l}\text { Perceived-benefits- } \\
\text { composite }\end{array}$ & $<->$ & Environmental attitude & 0.025 & 0.227 & 0.007 & 3.782 & $* * *$ \\
\hline Technology-attitude-positive & $<->$ & $\begin{array}{l}\text { Technology-attitude- } \\
\text { negative }\end{array}$ & -0.096 & -0.166 & 0.032 & -3.029 & 0.002 \\
\hline Technology-attitude-negative & $<-->$ & $\begin{array}{l}\text { Fear-and-anxiety- } \\
\text { composite }\end{array}$ & -0.040 & -0.195 & 0.014 & -2.926 & 0.003 \\
\hline Technology-attitude-positive & $<-->$ & $\begin{array}{l}\text { Fear-and-anxiety- } \\
\text { composite }\end{array}$ & 0.031 & 0.088 & 0.016 & 1.96 & 0.05 \\
\hline Car-ownership-attitude-2 & $<->$ & Environmental attitude & -0.017 & -0.092 & 0.008 & -2.048 & 0.041 \\
\hline Environmental attitude & $<->$ & Car-ownership-attitude-1 & 0.051 & 0.207 & 0.013 & 3.829 & $* * *$ \\
\hline Subjective norm & $<->$ & $\begin{array}{l}\text { Fear-and-anxiety- } \\
\text { composite }\end{array}$ & 0.100 & 0.537 & 0.016 & 6.464 & $* * *$ \\
\hline $\begin{array}{l}\text { Perceived-benefits- } \\
\text { composite }\end{array}$ & $<->$ & $\begin{array}{l}\text { Fear-and-anxiety- } \\
\text { composite }\end{array}$ & 0.035 & 0.390 & 0.008 & 4.151 & $* * *$ \\
\hline Image & $<->$ & $\begin{array}{l}\text { Fear-and-anxiety- } \\
\text { composite }\end{array}$ & 0.099 & 0.281 & 0.02 & 5.07 & $* * *$ \\
\hline Subjective norm & $<-->$ & $\begin{array}{l}\text { Perceived-benefits- } \\
\text { composite }\end{array}$ & 0.066 & 0.490 & 0.015 & 4.358 & $* * *$ \\
\hline Perceived behavioural control & $<->$ & Subjective norm & 0.091 & 0.239 & 0.017 & 5.192 & $* * *$ \\
\hline Perceived behavioural control & $<-->$ & $\begin{array}{l}\text { Technology-attitude- } \\
\text { positive }\end{array}$ & 0.140 & 0.196 & 0.029 & 4.814 & $* * *$ \\
\hline Education & $<-->$ & $\begin{array}{l}\text { Technology-attitude- } \\
\text { positive }\end{array}$ & 0.055 & 0.048 & 0.047 & 1.162 & 0.245 \\
\hline Education & $<->$ & Car-ownership-attitude-1 & -0.068 & -0.104 & 0.033 & -2.035 & 0.042 \\
\hline
\end{tabular}




\begin{tabular}{|c|c|c|c|c|c|c|c|}
\hline Education & $<-->$ & Car-ownership-attitude-2 & -0.054 & -0.111 & 0.024 & -2.252 & 0.024 \\
\hline Age & $<-->$ & $\begin{array}{l}\text { Technology-attitude- } \\
\text { negative }\end{array}$ & -1.004 & -0.112 & 0.505 & -1.989 & 0.047 \\
\hline Age & $<-->$ & $\begin{array}{l}\text { Fear-and-anxiety- } \\
\text { composite }\end{array}$ & -0.473 & -0.087 & 0.257 & -1.842 & 0.065 \\
\hline Gender & $<-->$ & $\begin{array}{l}\text { Fear-and-anxiety- } \\
\text { composite }\end{array}$ & -0.035 & -0.204 & 0.009 & -3.747 & $* * *$ \\
\hline Gender & $<-->$ & $\begin{array}{l}\text { Perceived-benefits- } \\
\text { composite }\end{array}$ & -0.03 & -0.24 & 0.008 & -3.79 & $* * *$ \\
\hline Gender & $<-->$ & $\begin{array}{l}\text { Technology-attitude- } \\
\text { negative }\end{array}$ & 0.057 & 0.198 & 0.017 & 3.301 & $* * *$ \\
\hline Gender & $<-->$ & Environmental attitude & 0.015 & 0.072 & 0.009 & 1.785 & 0.074 \\
\hline Gender & $<-->$ & Subjective norm & -0.032 & -0.123 & 0.012 & -2.63 & 0.009 \\
\hline \multicolumn{8}{|l|}{ B. Direct effects } \\
\hline Variables & & & B & B & SE & CR & $\mathbf{P}$ \\
\hline Perceived behavioural control & $<--$ & Subjective norm & 1.214 & 0.739 & 0.101 & 12.064 & $* * *$ \\
\hline Perceived-benefits- 2 & $<--$ & $\begin{array}{l}\text { Perceived behavioural } \\
\text { control }\end{array}$ & 0.193 & 0.232 & 0.059 & 3.255 & 0.001 \\
\hline Affective attitude & $<--$ & $\begin{array}{l}\text { Perceived behavioural } \\
\text { control }\end{array}$ & 0.284 & 0.41 & 0.043 & 6.666 & $* * *$ \\
\hline Perceived-benefits-1 & $<--$ & $\begin{array}{l}\text { Perceived behavioural } \\
\text { control }\end{array}$ & 0.187 & 0.292 & 0.043 & 4.335 & $* * *$ \\
\hline Perceived-benefits-1 & $<--$ & Subjective norm & 0.364 & 0.345 & 0.074 & 4.895 & $* * *$ \\
\hline Perceived-benefits- 2 & $<--$ & Subjective norm & 0.387 & 0.282 & 0.118 & 3.284 & 0.001 \\
\hline Perceived behavioural control & $<--$ & Education & 0.072 & 0.095 & 0.026 & 2.777 & 0.005 \\
\hline Perceived-benefits-1 & $<--$ & Education & 0.028 & 0.057 & 0.012 & 2.226 & 0.026 \\
\hline
\end{tabular}

Notes: $\beta=$ Unstandardized regression estimates; $b=$ standardized regression estimates; $S E=$ standard error; $C R=$ critical ratio; $\mathrm{P}=\mathrm{p}$-value; $* * * \mathrm{P}$-value $<0.01$

\subsection{Validation of the measurement models}

The four measurement models are validated, by testing for convergent validity and discriminant validity. Whereas the former tests whether measures of latent variables in each of the four models are in fact related, the latter tests whether the variables that are not supposed to be related are actually unrelated.

Table 7 shows the AVE and MSV values across the four measurement models. Across all measurement models, five out of the nine latent variables have $A V E$ values $\geq 0.5$. AV values for perceived-benefits-composite is less than the 0.5 threshold. However, each of the three latent variables that load onto this factor, namely affective attitude ( $A V E=0.699)$, perceivedbenefits-1 $(A V E=0.511)$ and perceived-benefits-2 $(A V E=0.574)$ have AV values higher than the minimum threshold, showing evidence of convergent validity. AVE values for subjective norm and technology-attitude-negative are also very close to the acceptable threshold of 0.5. In addition, the standardized factor loadings of subjective norm and technology-attitudenegative items across all measurement models are greater than the minimum acceptable value of 0.5 Moreover, comparing MSV values with AVE shows that across all four measurement models, MSV values are less than the AVE values of any two latent variables that are confirmed to be related. Together, the results demonstrate sufficient convergent and discriminant validity in the measurement models. 
Table 7: AVE and MSV values of measurement models showing evidence of convergent and discriminant validity

\begin{tabular}{|c|c|c|c|c|c|c|c|c|c|c|c|}
\hline \multicolumn{6}{|c|}{ Measurement model-1 } & \multicolumn{6}{|c|}{ Measurement model-2 } \\
\hline \multicolumn{2}{|c|}{ AVE } & \multirow[b]{2}{*}{$\begin{array}{l}\text { Fear-and-anxiety- } \\
\text { composite }\end{array}$} & \multirow[b]{2}{*}{$<-->$} & \multirow[b]{2}{*}{$\begin{array}{l}\text { Technology-attitude- } \\
\text { positive }\end{array}$} & \multirow{2}{*}{$\begin{array}{l}\text { MSV } \\
0.002\end{array}$} & \multicolumn{2}{|c|}{ AVE } & \multirow[b]{2}{*}{$\begin{array}{l}\text { Technology-attitude- } \\
\text { positive }\end{array}$} & \multirow[b]{2}{*}{$<->$} & \multirow[b]{2}{*}{$\begin{array}{l}\text { Fear-and-anxiety- } \\
\text { composite }\end{array}$} & \multirow{2}{*}{$\frac{\text { MSV }}{0.006}$} \\
\hline $\begin{array}{l}\text { Perceived- } \\
\text { benefits- } \\
\text { composite }\end{array}$ & 0.275 & & & & & $\begin{array}{l}\text { Perceived-benefits- } \\
\text { composite }\end{array}$ & 0.278 & & & & \\
\hline $\begin{array}{l}\text { Fear-and- } \\
\text { anxiety- } \\
\text { composite }\end{array}$ & 0.741 & $\begin{array}{l}\text { Fear-and-anxiety- } \\
\text { composite }\end{array}$ & $<-->$ & $\begin{array}{l}\text { Perceived-benefits- } \\
\text { composite }\end{array}$ & 0.127 & $\begin{array}{l}\text { Fear-and-anxiety- } \\
\text { composite }\end{array}$ & 0.740 & $\begin{array}{l}\text { Perceived-benefits- } \\
\text { composite }\end{array}$ & $<->$ & $\begin{array}{l}\text { Fear-and-anxiety- } \\
\text { composite }\end{array}$ & 0.141 \\
\hline Image & 0.930 & $\begin{array}{l}\text { Fear-and-anxiety- } \\
\text { composite }\end{array}$ & $<->$ & Image & 0.089 & Image & 0.930 & Image & $<->$ & $\begin{array}{l}\text { Fear-and-anxiety- } \\
\text { composite }\end{array}$ & 0.087 \\
\hline $\begin{array}{l}\text { Subjective } \\
\text { norm }\end{array}$ & 0.432 & Subjective norm & $<-->$ & Image & 0.197 & Subjective norm & 0.430 & Subjective norm & $<->$ & Image & 0.195 \\
\hline $\begin{array}{l}\text { Technology- } \\
\text { attitude- } \\
\text { positive }\end{array}$ & 0.797 & $\begin{array}{l}\text { Fear-and-anxiety- } \\
\text { composite }\end{array}$ & $<-->$ & Subjective norm & 0.311 & $\begin{array}{l}\text { Technology- } \\
\text { attitude-positive }\end{array}$ & 0.790 & Subjective norm & $<->$ & $\begin{array}{l}\text { Fear-and-anxiety- } \\
\text { composite }\end{array}$ & 0.301 \\
\hline \multirow[t]{11}{*}{$\begin{array}{l}\text { Technology- } \\
\text { attitude- } \\
\text { negative }\end{array}$} & 0.461 & $\begin{array}{l}\text { Technology-attitude- } \\
\text { negative }\end{array}$ & $\langle-->$ & $\begin{array}{l}\text { Perceived-benefits- } \\
\text { composite }\end{array}$ & 0.027 & $\begin{array}{l}\text { Technology- } \\
\text { attitude-negative }\end{array}$ & 0.458 & $\begin{array}{l}\text { Technology-attitude- } \\
\text { negative }\end{array}$ & $\langle--\rangle$ & $\begin{array}{l}\text { Perceived- } \\
\text { benefits- } \\
\text { composite }\end{array}$ & 0.031 \\
\hline & & $\begin{array}{l}\text { Technology-attitude- } \\
\text { positive }\end{array}$ & $<->$ & $\begin{array}{l}\text { Perceived-benefits- } \\
\text { composite }\end{array}$ & 0.032 & $\begin{array}{l}\text { Environmental } \\
\text { attitude }\end{array}$ & 0.675 & $\begin{array}{l}\text { Technology-attitude- } \\
\text { positive }\end{array}$ & $<->$ & $\begin{array}{l}\text { Perceived- } \\
\text { benefits- } \\
\text { composite }\end{array}$ & 0.028 \\
\hline & & $\begin{array}{l}\text { Fear-and-anxiety- } \\
\text { composite }\end{array}$ & $<-->$ & $\begin{array}{l}\text { Technology-attitude- } \\
\text { negative }\end{array}$ & 0.035 & $\begin{array}{l}\text { Collaborative } \\
\text { consumption } \\
\text { attitude }\end{array}$ & 0.527 & $\begin{array}{l}\text { Technology-attitude- } \\
\text { negative }\end{array}$ & $<->$ & $\begin{array}{l}\text { Fear-and-anxiety- } \\
\text { composite }\end{array}$ & 0.035 \\
\hline & & $\begin{array}{l}\text { Technology-attitude- } \\
\text { positive }\end{array}$ & $<-->$ & $\begin{array}{l}\text { Technology-attitude- } \\
\text { negative }\end{array}$ & 0.014 & & & $\begin{array}{l}\text { Technology-attitude- } \\
\text { positive }\end{array}$ & $<->$ & $\begin{array}{l}\text { Technology- } \\
\text { attitude-negative }\end{array}$ & 0.034 \\
\hline & & Subjective norm & & $\begin{array}{l}\text { Perceived-benefits- } \\
\text { composite }\end{array}$ & 0.225 & & & Subjective norm & $<->$ & $\begin{array}{l}\text { Perceived- } \\
\text { benefits- } \\
\text { composite }\end{array}$ & 0.232 \\
\hline & & $\begin{array}{l}\text { Perceived-behavioural- } \\
\text { control }\end{array}$ & & Subjective norm & 0.036 & & & $\begin{array}{l}\text { Perceived-benefits- } \\
\text { composite }\end{array}$ & $<->$ & $\begin{array}{l}\text { Environmental } \\
\text { attitude }\end{array}$ & 0.033 \\
\hline & & $\begin{array}{l}\text { Perceived-behavioural- } \\
\text { control }\end{array}$ & & $\begin{array}{l}\text { Technology-attitude- } \\
\text { positive }\end{array}$ & 0.102 & & & $\begin{array}{l}\text { Collaborative } \\
\text { consumption attitude }\end{array}$ & $<->$ & $\begin{array}{l}\text { Environmental } \\
\text { attitude }\end{array}$ & 0.264 \\
\hline & & & & & & & & $\begin{array}{l}\text { Technology-attitude- } \\
\text { positive }\end{array}$ & $\langle->$ & $\begin{array}{l}\text { Environmental } \\
\text { attitude }\end{array}$ & 0.214 \\
\hline & & & & & & & & $\begin{array}{l}\text { Collaborative } \\
\text { consumption attitude }\end{array}$ & & $\begin{array}{l}\text { Technology- } \\
\text { attitude-positive }\end{array}$ & 0.235 \\
\hline & & & & & & & & $\begin{array}{l}\text { Perceived-behavioural- } \\
\text { control }\end{array}$ & & $\begin{array}{l}\text { Technology- } \\
\text { attitude-positive }\end{array}$ & 0.038 \\
\hline & & & & & & & & $\begin{array}{l}\text { Perceived-behavioural- } \\
\text { control }\end{array}$ & & Subjective norm & 0.059 \\
\hline
\end{tabular}


Table 7: AVE and MSV values of measurement models showing evidence of convergent and discriminant validity

\begin{tabular}{|c|c|c|c|c|c|c|c|c|c|c|c|}
\hline \multicolumn{6}{|c|}{ Measurement model-3 } & \multicolumn{6}{|c|}{ Measurement model-4 } \\
\hline \multicolumn{2}{|c|}{ AVE } & \multirow[b]{2}{*}{$\begin{array}{l}\text { Technology-attitude- } \\
\text { positive }\end{array}$} & \multirow[b]{2}{*}{$<-->$} & \multirow[b]{2}{*}{$\begin{array}{l}\text { Fear-and-anxiety- } \\
\text { composite }\end{array}$} & \multirow{2}{*}{\begin{tabular}{c|} 
MSV \\
0.005
\end{tabular}} & \multicolumn{2}{|c|}{ AVE } & \multirow[b]{2}{*}{$\begin{array}{l}\text { Technology-attitude- } \\
\text { positive }\end{array}$} & \multirow[b]{2}{*}{$<-->$} & \multirow[b]{2}{*}{$\begin{array}{l}\text { Fear-and-anxiety- } \\
\text { composite }\end{array}$} & \multirow{2}{*}{$\frac{\text { MSV }}{0.007}$} \\
\hline $\begin{array}{l}\text { Perceived- } \\
\text { benefits- } \\
\text { composite }\end{array}$ & 0.287 & & & & & $\begin{array}{l}\text { Perceived- } \\
\text { benefits- } \\
\text { composite }\end{array}$ & 0.287 & & & & \\
\hline $\begin{array}{l}\text { Fear-and- } \\
\text { anxiety- } \\
\text { composite }\end{array}$ & 0.740 & $\begin{array}{l}\text { Perceived-benefits- } \\
\text { composite }\end{array}$ & $<->$ & $\begin{array}{l}\text { Fear-and-anxiety- } \\
\text { composite }\end{array}$ & 0.144 & $\begin{array}{l}\text { Fear-and- } \\
\text { anxiety- } \\
\text { composite }\end{array}$ & 0.740 & Image & $<->$ & $\begin{array}{l}\text { Fear-and-anxiety- } \\
\text { composite }\end{array}$ & 0.088 \\
\hline Image & 0.930 & Image & $<->$ & $\begin{array}{l}\text { Fear-and-anxiety- } \\
\text { composite }\end{array}$ & 0.086 & Image & 0.930 & $\begin{array}{l}\text { Technology-attitude- } \\
\text { negative }\end{array}$ & $<->$ & $\begin{array}{l}\text { Fear-and-anxiety- } \\
\text { composite }\end{array}$ & 0.036 \\
\hline $\begin{array}{l}\text { Subjective } \\
\text { norm }\end{array}$ & 0.435 & $\begin{array}{l}\text { Technology-attitude- } \\
\text { negative }\end{array}$ & $<->$ & $\begin{array}{l}\text { Fear-and-anxiety- } \\
\text { composite }\end{array}$ & 0.036 & Subjective norm & 0.435 & $\begin{array}{l}\text { Technology-attitude- } \\
\text { positive }\end{array}$ & $<->$ & Environmental-attitude & 0.214 \\
\hline $\begin{array}{l}\text { Technology- } \\
\text { attitude- } \\
\text { positive }\end{array}$ & 0.792 & $\begin{array}{l}\text { Technology-attitude- } \\
\text { positive }\end{array}$ & $<->$ & $\begin{array}{l}\text { Environmental- } \\
\text { attitude }\end{array}$ & 0.153 & $\begin{array}{l}\text { Technology- } \\
\text { attitude- } \\
\text { positive }\end{array}$ & 0.790 & Subjective norm & $<->$ & $\begin{array}{l}\text { Perceived-benefits- } \\
\text { composite }\end{array}$ & 0.204 \\
\hline $\begin{array}{l}\text { Technology- } \\
\text { attitude- } \\
\text { negative }\end{array}$ & 0.460 & Public-transit-attitude & $<-->$ & $\begin{array}{l}\text { Perceived-benefits- } \\
\text { composite }\end{array}$ & 0.018 & $\begin{array}{l}\text { Technology- } \\
\text { attitude- } \\
\text { negative }\end{array}$ & 0.460 & Subjective norm & $<->$ & $\begin{array}{l}\text { Fear-and-anxiety- } \\
\text { composite }\end{array}$ & 0.296 \\
\hline $\begin{array}{l}\text { Environmental } \\
\text { attitude }\end{array}$ & 0.667 & Subjective norm & $<->$ & $\begin{array}{l}\text { Perceived-benefits- } \\
\text { composite }\end{array}$ & 0.204 & $\begin{array}{l}\text { Environmental } \\
\text { attitude }\end{array}$ & 0.677 & Subjective norm & $<->$ & Image & 0.197 \\
\hline \multirow[t]{11}{*}{$\begin{array}{l}\text { Public transit } \\
\text { attitude }\end{array}$} & 0.502 & $\begin{array}{l}\text { Technology-attitude- } \\
\text { positive }\end{array}$ & $<->$ & $\begin{array}{l}\text { Perceived-benefits- } \\
\text { composite }\end{array}$ & 0.033 & $\begin{array}{l}\text { Car-ownership } \\
\text { attitude-1 }\end{array}$ & 0.502 & $\begin{array}{l}\text { Technology-attitude- } \\
\text { positive }\end{array}$ & $<->$ & $\begin{array}{l}\text { Technology-attitude- } \\
\text { negative }\end{array}$ & 0.029 \\
\hline & & $\begin{array}{l}\text { Technology-attitude- } \\
\text { negative }\end{array}$ & $<->$ & $\begin{array}{l}\text { Perceived-benefits- } \\
\text { composite }\end{array}$ & 0.039 & $\begin{array}{l}\text { Car-ownership } \\
\text { attitude-2 }\end{array}$ & 0.614 & Car_ownership_attitude_2 & $<->$ & Car_ownership_attitude_1 & 0.066 \\
\hline & & Subjective norm & $<->$ & $\begin{array}{l}\text { Fear-and-anxiety- } \\
\text { composite }\end{array}$ & 0.298 & & & $\begin{array}{l}\text { Perceived-benefits- } \\
\text { composite }\end{array}$ & $<->$ & $\begin{array}{l}\text { Fear-and-anxiety- } \\
\text { composite }\end{array}$ & 0.140 \\
\hline & & Subjective norm & $<->$ & Image & 0.197 & & & $\begin{array}{l}\text { Technology-attitude- } \\
\text { negative }\end{array}$ & $<->$ & $\begin{array}{l}\text { Perceived-benefits- } \\
\text { composite }\end{array}$ & 0.041 \\
\hline & & $\begin{array}{l}\text { Technology-attitude- } \\
\text { positive }\end{array}$ & $<->$ & $\begin{array}{l}\text { Technology-attitude- } \\
\text { negative }\end{array}$ & 0.025 & & & $\begin{array}{l}\text { Technology-attitude- } \\
\text { positive }\end{array}$ & $<->$ & Car_ownership_attitude_1 & 0.060 \\
\hline & & $\begin{array}{l}\text { Perceived-benefits- } \\
\text { composite }\end{array}$ & $<->$ & $\begin{array}{l}\text { Environmental- } \\
\text { attitude }\end{array}$ & 0.049 & & & $\begin{array}{l}\text { Technology-attitude- } \\
\text { positive }\end{array}$ & $<->$ & $\begin{array}{l}\text { Perceived-benefits- } \\
\text { composite }\end{array}$ & 0.042 \\
\hline & & Public-transit-attitude & & $\begin{array}{l}\text { Environmental- } \\
\text { attitude }\end{array}$ & 0.141 & & & Car_ownership_attitude_2 & $<-->$ & Environmental-attitude & 0.011 \\
\hline & & $\begin{array}{l}\text { Perceived-behavioural- } \\
\text { control }\end{array}$ & & $\begin{array}{l}\text { Technology-attitude- } \\
\text { positive }\end{array}$ & 0.057 & & & Environmental-attitude & $<->$ & Car_ownership_attitude_1 & 0.040 \\
\hline & & $\begin{array}{l}\text { Perceived-behavioural- } \\
\text { control }\end{array}$ & & Subjective norm & 0.053 & & & $\begin{array}{l}\text { Perceived-benefits- } \\
\text { composite }\end{array}$ & & Environmental-attitude & 0.052 \\
\hline & & & & & & & & $\begin{array}{l}\text { Perceived-behavioural- } \\
\text { control }\end{array}$ & & $\begin{array}{l}\text { Technology-attitude- } \\
\text { positive }\end{array}$ & 0.038 \\
\hline & & & & & & & & $\begin{array}{l}\text { Perceived-behavioural- } \\
\text { control }\end{array}$ & & Subjective norm & 0.058 \\
\hline
\end{tabular}




\section{Discussion and conclusion}

In this paper, we have argued that improving behavioural realism in AV user adoption studies, would be fundamental to a reliable estimation of the diffusion of self-driving vehicles and to the study of their long-term impact on travel behaviours. To this end, we problematized AV user adoption and diffusion as questions requiring a sound conceptual foundation, as well as a robust statistical analysis technique that can allow researchers to represent the interplay among multiple behavioural factors. In order to advance conceptual models addressing different aspects of AV user adoption behaviour, we synthesized the principles of existing theories in social-psychology, social-ecology, and technology and innovation studies.

In practice, the proposed behavioural models of AV user adoption deploy a set of latent variables and their corresponding indicators, which would serve as the behavioural antecedents to understand and predict adoption and diffusion of autonomous vehicles. The models we advance integrate relevant socio-demographic variables, and latent behavioural factors, including perceived benefits and perceived ease of use of AVs, public fears and anxieties regarding AVs, subjective norm, perceived behavioural control, and attitudinal factors covering the environment, technology, collaborative consumption, public transit and car ownership. Using confirmatory factor analysis on the empirical data obtained through an online survey, we have specified four measurement models in which we tested and validated a series of hypothesized relationships among the variables in our conceptual models.

The first model (i.e. measurement model-1), which is intended for studies seeking to identify the behavioural determinants of $\mathrm{AV}$ adoption intentions, comprises seven latent variables. These latent variables reflect individuals' perception of the benefits of $A V s$, the perception of ease of use of AVs, perceived behavioural control, and the role of social environment factors captured through subjective norm and image variables. We also included a proximal attitudinal variable to capture how individuals perceive technological advancement in general, beyond the specific case of autonomous vehicles. At the core of the second, third and fourth measurement models are the aforementioned latent variables and additional variables considered relevant depending on the objective of the research. The second model (i.e. measurement model-2) is intended for use in studies where the objective is to identify the factors that predict whether or not individuals would prefer to use AV-sharing services. In view of this, we included two latent variables that captures individuals' attitude towards collaborative consumption/sharing and the environment. The third model (i.e. measurement models-3) would be deployed in studies where the objective is to predict whether or not members of a given population would prefer to use AV public transport services. To this end, we included in this model, the public's perception of and attitude towards public transit as one of the relevant predictors. The fourth model (i.e. measurement model-4) is intended for application in research where the objective is to identify the behavioural factors underlying individuals' preference for ownership of AVs. In view of this, we integrated attitude towards car-ownership as the additional latent variable. Across the four measurement models, we 
have demonstrated convergent and discriminant validity for a number of hypothesized relationships among the latent variables. This means that the various hypotheses presented in the four conceptual models (see Fig 3, 4, 5 and 6) are indeed supported by the empirical data. The main findings are discussed as follows:

\section{Relationships among pro-technology attitudes, public fears and anxieties, and perceived benefits and ease of use of self-driving cars}

In our conceptual models we hypothesized that public fears and anxieties regarding AVs will covary with attitudes towards technology and perceived benefits of AVs. Results of the confirmatory factor analysis show that public fears and anxieties regarding automated driving correlate positively with pro-technology attitudes in general, and perceived benefits of selfdriving cars in particular. One would expect the reverse given the fact that across the items measuring public fears and anxieties regarding $A V s$, the majority of our respondents (i.e. 64$71 \%$ ) indicated that they were actually concerned about AVs interaction with other road users (i.e. cyclists, pedestrians and motorists), as well as the potential failures of the technology. On the contrary, what we find from the survey data is that the majority of the respondents expect positive benefits from AVs. Indeed, on 13 out of the 16 items constituting perceived benefits of $A V s$ in our measurement models, the responses of more than half the survey participants show that they expect AVs to provide positive benefits. Previous research, conducted mainly in the USA (see e.g. Woldeamanuel and Nguyen, 2018; Bansal et al., 2016; Bansal and Kockelman, 2017; Hardman et al., 2018) show similar high perceptions of AV usefulness among participants. Furthermore, more than $80 \%$ of our respondents indicated that technological advancements in general would bring positive benefits to society. Taken together, what these findings suggest is that although genuine fears exist in the population regarding the safety and security risks of automating driving, the overall outlook of our respondents with respect to technological advancement and its benefits in the form of $A V$, remains positive.

Moreover, we hypothesized that individuals' attitude towards the environment and attitude towards collaborative consumption will covary and that these latent attitudinal variables will also vary in correlation with attitudes towards technology. We also posited that environmental attitudes will covary with attitude towards public transport and car ownership. Results of the statistical modelling show that environmental attitudes, collaborative consumption attitudes and technology attitudes correlate positively with each other. Previous studies have found that in certain contexts, environmental sustainability motivations underpin participation in access-based/ collaborative consumption schemes (see e.g. Hamari et al., 2016; Mont, 2004; Gansky, 2010). Also, the evidence suggests that people tend to agree that technological progress would contribute to achieving environmental sustainability imperatives (Milfont and Duckitt, 2010), hence the strong positive relationship between individuals' attitude towards the environment and technology. We also find a positive 
association between attitude towards the environment and attitude towards public transit, while the latent variable comprising indicator items used to measure our respondents perception of the environmental impacts of car ownership (i.e. car-ownership attitude-2) correlates negatively with pro-environmental attitudes. This implies that our respondents associate public transit use with being environmentally friendly.

\section{Relationships among perceived benefits of AVs and general attitudes towards technology, the environment, collaborative consumption and different transport modes}

We also postulated in our second conceptual model (CM-2) that attitude towards technology, the environment and collaborative consumption will each covary with perceived benefits of AVs. In CM-3, we posited an association between perceived benefits of AVs and attitude towards public transit use. Results of the confirmatory factor analysis show that our composite measure of perceived benefits of AVs (i.e. perceived-benefits-composite), which is made up of affective attitude towards AVs, expected instrumental utility of commuting in an $\mathrm{AV}$ and the benefits of being able to conduct activities on-board an AV, correlate positively with pro-environmental and pro-technology attitudes across all the validated measurement models. On the contrary, negative attitude towards technology correlates negatively with both pro-technology attitudes and perceived benefits of AVs. Given that automated driving technologies are essentially new, it is reasonable that overall perception of their utility increases among people with positive attitude towards technology. The negative relationship between $\mathrm{AV}$ benefits and negative attitude towards technology on the other hand, could reflect individuals' suspicion about technological fixes in general, and the potential loss of employment that automated technologies such as self-driving cars could bring. Indeed, our latent variable measuring negative attitudes towards technology captured these sentiments from the study participants. In the second and third measurement models respectively, we found that perceived benefits of AVs correlate positively with pro-collaborative consumption attitudes and favourable attitudes towards public transit. The reasons for the directions of effect among the aforementioned variables are given as follows: The set of indicator items we used to measure individuals' perception of the benefits of AVs, capture a wide range of potential outcomes which reflect (a) the utilitarian benefits currently provided by different modes of conventional motorized transport (i.e. public transit and car-sharing), and (b) the environmental consequences of motorized transport (i.e. congestion, air and noise pollution). Thus, the positive association between expected AV benefits and pro-public transit attitudes could stem from the fact that from the survey, a significant proportion of our respondents expect both environmental and commuting benefits from AVs, some of which are currently being met by conventional public transit. In a similar vein, the positive association between environmental attitudes and perceived benefits of AVs is expected because as the results of the survey show, the majority of our respondents hold pro-environmental attitudes and also agree that the benefits of AVs would include some environmental benefits such as reducing traffic congestion and environmental pollution. 


\section{The impact of perceived control and of the external social environment}

Consistent with insights from the original TAM models integrated in our conceptual models of AV user adoption behaviour, we have demonstrated that across all the four measurement models, subjective norm directly predicts first-level latent measures of perceived benefits of AVs (i.e. perceived-benefits- 1 and perceived-benefits-2), as well as perceived ease of use of automated driving technology. Indeed, the results show that a significant number of the respondents agreed that AVs will become the dominant mode of transportation in the future $(56 \%)$ and that seeing significant others (i.e. friend and colleagues) use self-driving vehicles will push them to do same (37\%)-see Table 2 . Subjective norm predicting perceived benefits of AVs as hypothesized in our conceptual models, therefore, implies that our respondents associate the potential positive benefits of self-driving cars, with acceptance of AVs by other members of the population. In addition to the above, we hypothesized that subjective norm would predict individuals' perception of ease of use of AVs. Results of our measurement models confirm this hypothesis, suggesting that perception of the ease of use of AVs would increase in the population as AVs become the norm, and individuals see significant others, including relatives and colleagues use self-driving vehicles.

Furthermore, we hypothesized in our conceptual models that subjective norm and perceived behavioural control variables are related. We test this hypothesis in our measurement models and find that subjective norm and perceived behavioural control are positively correlated. What this finding suggests is that while the majority of our respondents (73\%) believe that they have control over whether or not they use self-driving cars, they also acknowledge that seeing significant others such as friends, relatives and colleagues use AVs would have positive influence on their own adoption decisions. The findings of the survey further show that only a few of our respondents agreed that they would gain respect and recognition among their friends and colleagues (15\%) and/or in their communities (17\%) by using AVs. Yet, results of the confirmatory factor analysis in our measurement models indicate that image and subjective norm variables are positively correlated. This suggests that among the few individuals who believe that using AVs would confer recognition and reputation, the two variables measuring social environment effect in our models (i.e. subjective norm and image) appear to positively reinforce each other. Another finding from our study is that perceived behavioural control with respect to $\mathrm{AV}$ adoption and use correlates positively with protechnology attitudes. According to Ajzen's original TPB, perceived behavioural control partly reflects an individual's belief of confidence in being able to undertake a particular action, which in the context of our study is using AVs. It is therefore reasonable that favourable attitudes towards technology, which implicitly suggests openness to accept and use new technologies, increase with belief of control and confidence in using AVs among our respondents. 


\section{The role of socio-demographic factors-education, age and gender}

Finally, we show the effects of socio-demographic factors across the four measurement models. The results show that controlling for the other variables, higher level educational attainment correlates positively with pro-technology attitudes, and favourable attitudes towards the environment and collaborative consumption, but negatively with attitude towards car ownership/use. Also, higher educational attainment has a positive predictive effect on our respondents' perception of the potential commuting benefits of AVs (i.e. perceived-benefits-1) and perception of ease of use of AVs. Age has a negative predictive effect on perceived-benefits of AVs (i.e. perceived-benefits-2), suggesting that perception of expected benefits in the form of travel time use in recreational and/or productive activities while traveling in a driverless car decreases among older population. Moreover, gender correlates negatively with the overall perceived benefits of AVs (i.e. perceived-benefitscomposite), public fears and anxiety regarding driverless cars, subjective norm and image. Within the context of our survey data, we found that females are more likely to be sceptical about the benefits of technological advancement to society in general. They are also more likely to agree that AVs could have potential negative safety and security impacts and disagree that AVs would bring about positive benefits such as saving lives, providing comfortable and reliable travel and reducing congestion and travel-related pollution. Also, females are less likely to agree that AVs becoming the norm, seeing significant others use AVs, and the reputational benefits of using AVs would necessarily influence their own adoption decisions.

The empirical, theoretical and methodological contributions of this paper are intended for application in future research on AV user adoption behaviour in different urban contexts. Each of the four measurement models we have advanced contains latent behavioural variables, their corresponding indicator measures and pairs of empirically validated relationships which would be useful in predicting $A V$ interest and adoption intentions, and ownership, sharing and public transport adoption decisions with respect to self-driving vehicles.

\section{Acknowledgement}

This research was funded by the Irish Research Council (IRC) under the New Horizons Interdisciplinary Research Award for the project: Surpass-how shared autonomous cars will transform cities. 


\section{Appendix 1}

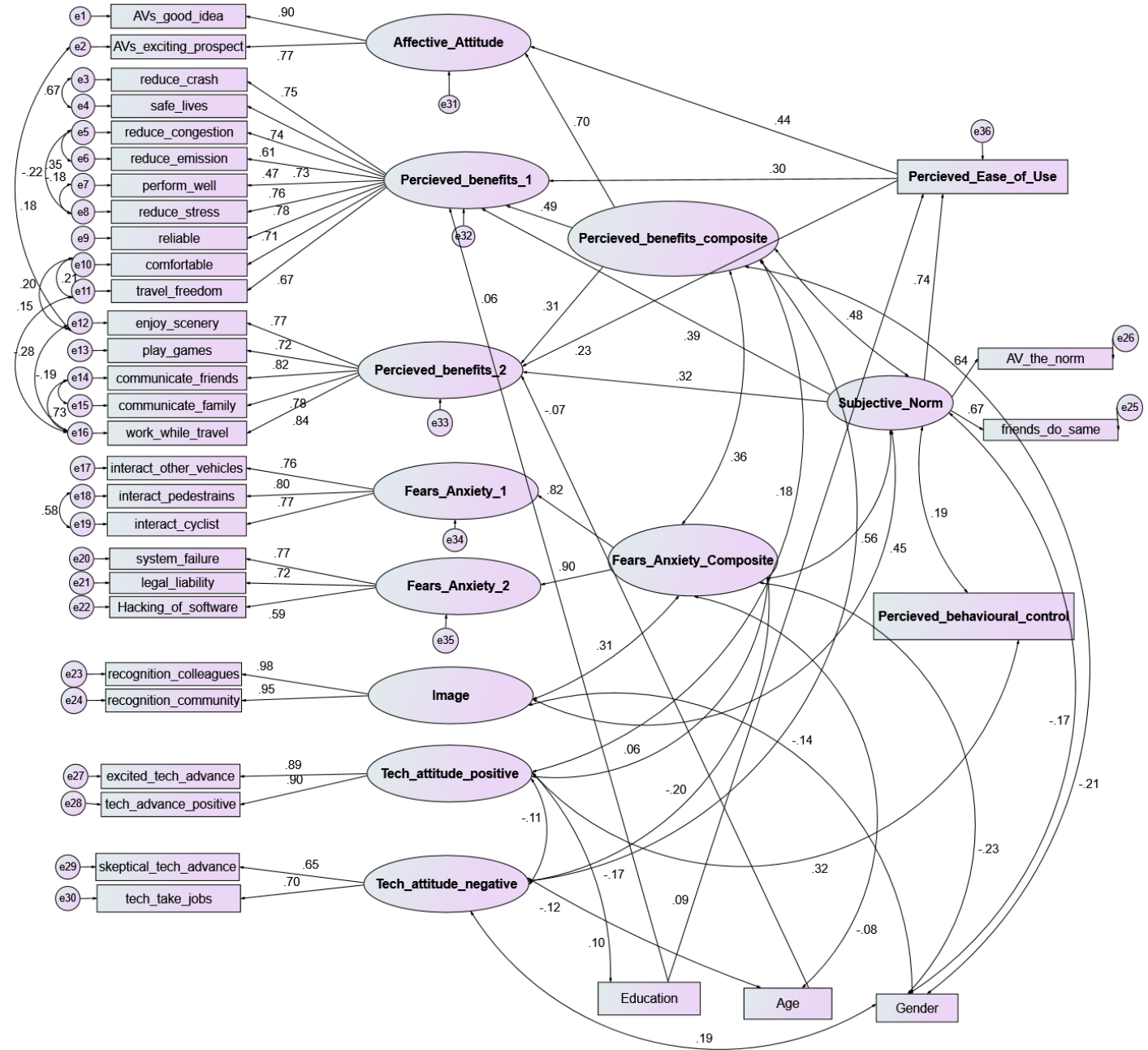

Fig 7 -Path diagram of Measurement Model-1: Model identification indices: $\chi^{2}=1029.727, \mathrm{df}=521$, Normed- $\chi^{2}=1.976$ $\mathrm{p}<0.01 ; \mathrm{RMSEA}=0.044 ; \mathrm{NFI}=0.907 ; \mathrm{CFI}=0.951 ; \mathrm{IFI}=0.952 ; \mathrm{TLI}=0.941 ; \mathrm{RFI}=0.907$. Overall scale reliability of response items $(\alpha)=0.906$ 

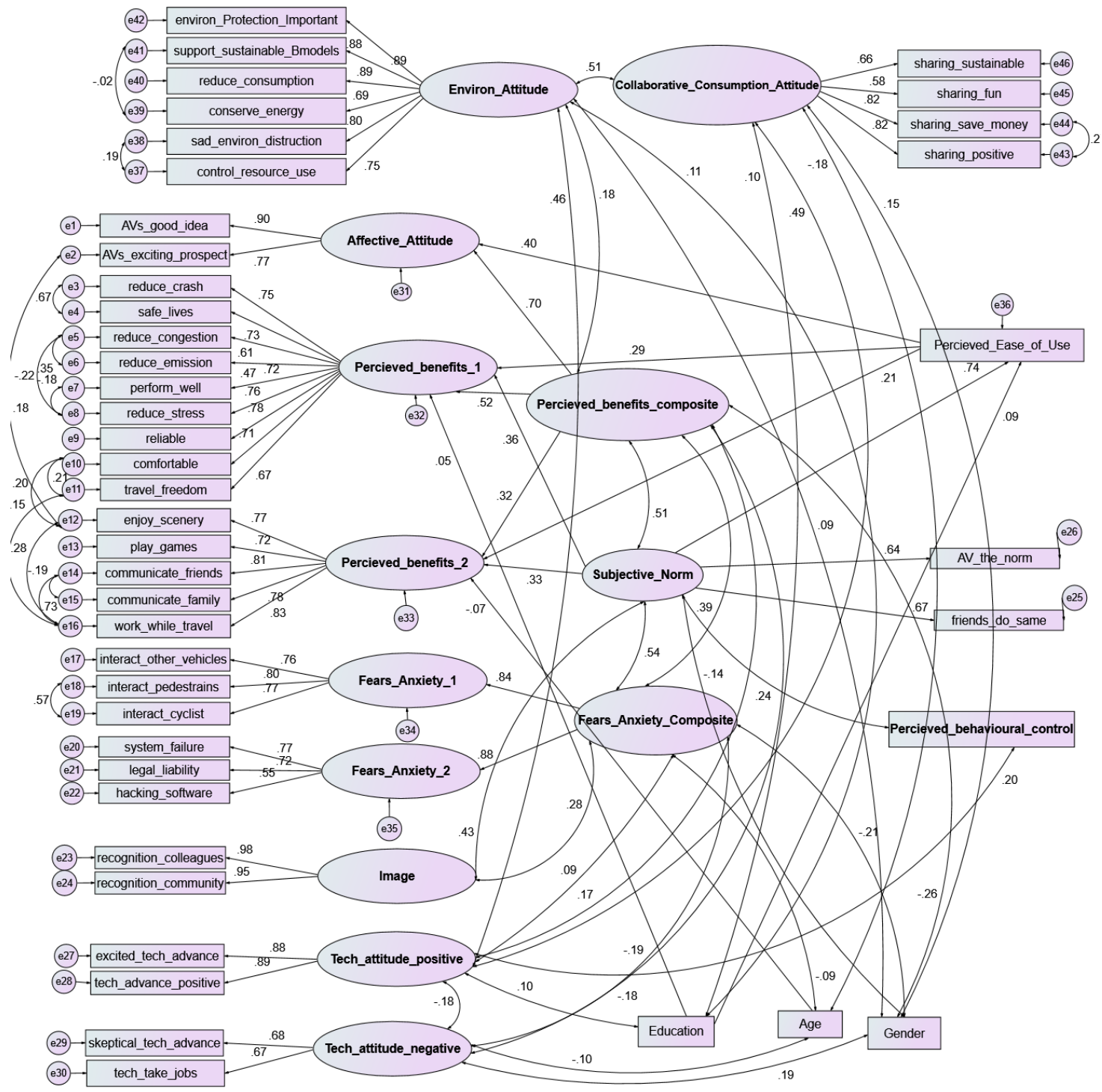

Fig 10 -Path diagram of Measurement Model-2: Model identification indices: $\chi^{2}=1579.814, \mathrm{df}=895$, Normed- $\chi^{2}=$ 1.765, $\mathrm{p}<0.01 ; \mathrm{RMSEA}=0.039 ; \mathrm{NFI}=0.904 ; \mathrm{CFI}=0.964 ; \mathrm{IFI}=0.951 ; \mathrm{TLI}=0.943 ; \mathrm{RFI}=0.908$. Overall scale reliability of response items $(\alpha)=0.909$ 


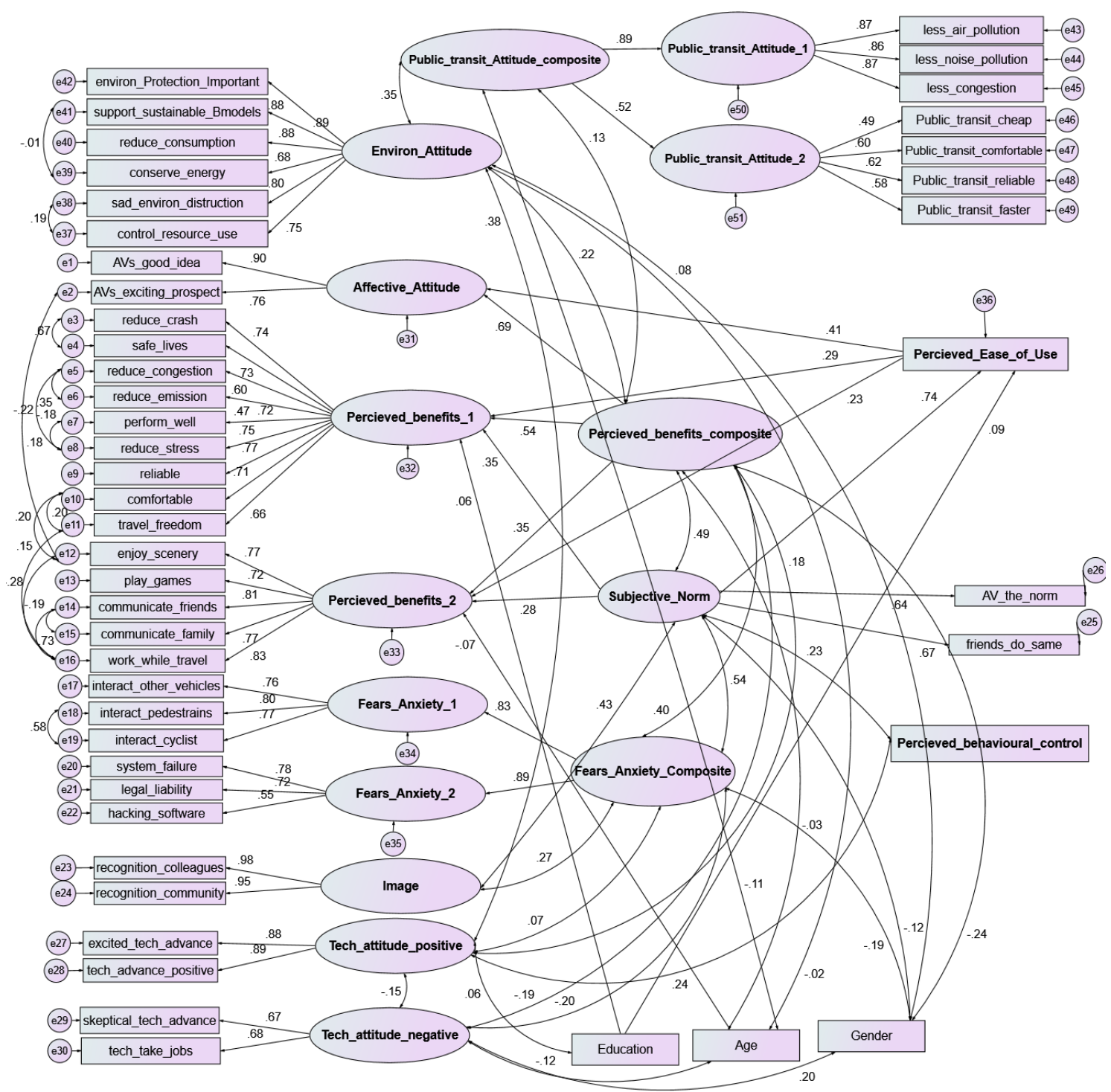

Fig12 -Path diagram of Measurement Model-3: Model identification indices: $\chi^{2}=1790.081, \mathrm{df}=1031$, Normed- $\chi^{2}=$ 1.736, $\mathrm{p}<0.01 ; \mathrm{RMSEA}=0.038 ; \mathrm{NFI}=0.904 ; \mathrm{CFI}=0.947 ; \mathrm{IFI}=0.947 ; \mathrm{TLI}=0.939 ; \mathrm{RFI}=0.90$. Overall scale reliability of response items $(\alpha)=0.894$ 


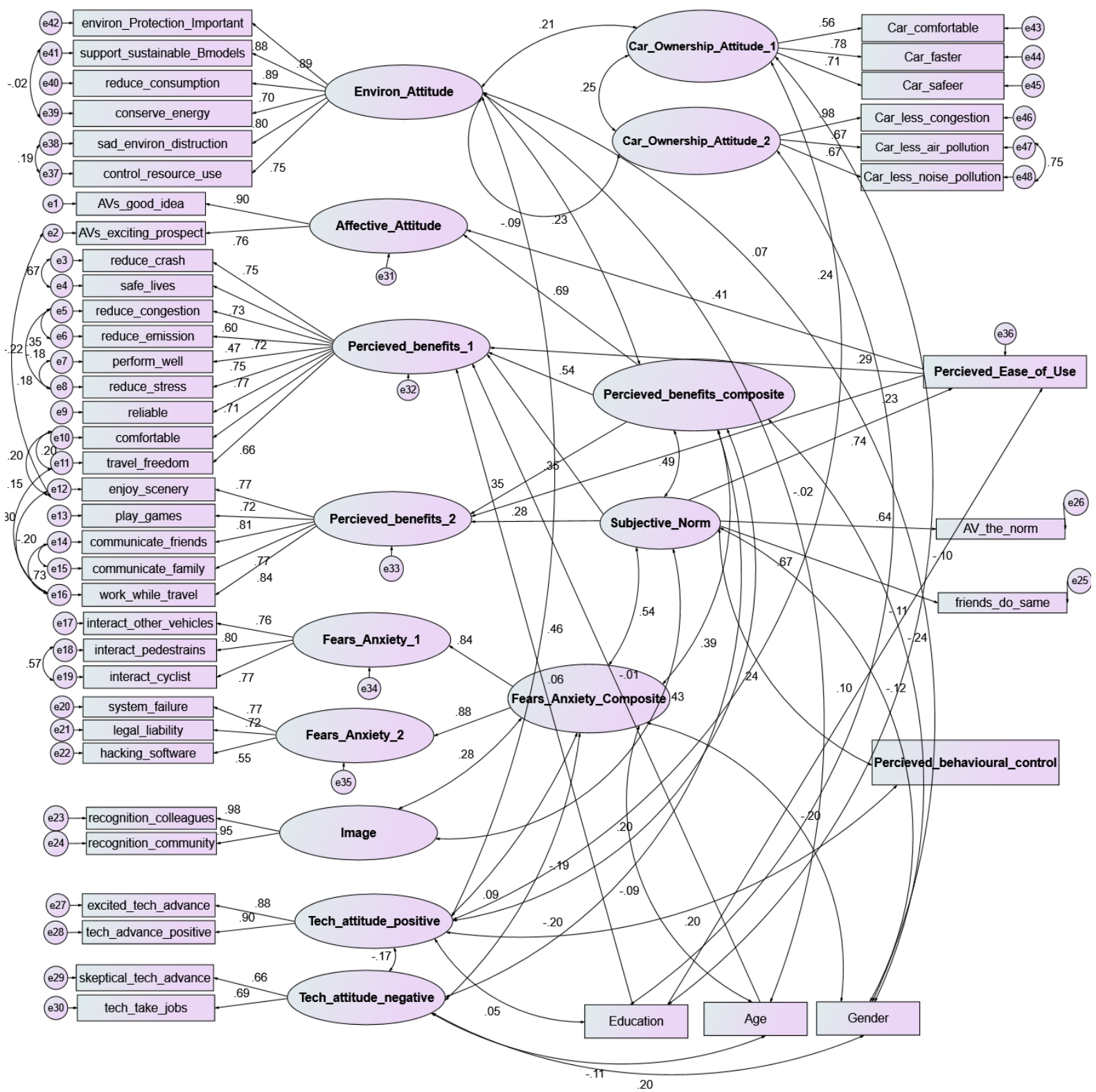

Fig 14 -Path diagram of Measurement Model-4: Model identification indices: $\chi^{2}=1759.495, \mathrm{df}=983$, Normed- $\chi^{2}=$ 1.789, $\mathrm{p}<0.01 ; \mathrm{RMSEA}=0.040 ; \mathrm{NFI}=0.906 ; \mathrm{CFI}=0.946 ; \mathrm{IFI}=0.946 ; \mathrm{TLI}=0.938 ; \mathrm{RFI}=0.901$. Overall scale reliability of response items $(\alpha)=0.894$

\section{References}

Acheampong, R. A., \& Siiba, A. (2018). Examining the determinants of utility bicycling using a socio-ecological framework: An exploratory study of the Tamale Metropolis in Northern Ghana. Journal of Transport Geography, 69, 1-10. https://doi.org/10.1016/j.jtrangeo.2018.04.004

Adnan, N., Nordin, S. M., bin Bahruddin, M. A., \& Ali, M. (2018). How trust can drive forward the user acceptance to the technology? In-vehicle technology for autonomous vehicle. Transportation Research Part A: Policy and Practice, 118, 819-836. 
Ajzen, I., (1991). The theory of planned behaviour. Organizational Behaviour and Human Decision Processes 50, 179-211.

Badland, H. et al., (2013). Socio-ecological predictors of the uptake of cycling for recreation and transport in adults: Results from the RESIDE study. Preventive Medicine, 57(4), pp. 396399.

Bansal, P., \& Kockelman, K. M. (2017). Forecasting Americans' long-term adoption of connected and autonomous vehicle technologies. Transportation Research Part A: Policy and Practice, 95, 49-63.

Bansal, P., Kockelman, K. M., \& Singh, A. (2016). Assessing public opinions of and interest in new vehicle technologies: an Austin perspective. Transportation Research Part C: Emerging Technologies, 67, 1-14.

Bamberg S., I. Ajzen, and P. Schmidt (2003). Choice of travel mode in the theory of planned behavior: The roles of past behavior, habit, and reasoned action. Basic and Applied Social Psychology 25: 175-187.

Bardhi, F., \& Eckhardt, G. M. (2012). Access-based consumption: The case of car sharing. Journal of consumer research, 39(4), 881-898.

Barnes, S. J., \& Mattsson, J. (2016). Understanding current and future issues in collaborative consumption: A four-stage Delphi study. Technological Forecasting and Social Change, 104, 200-211.

Botsman, R., \& Rogers, R. (2010). What's mine is yours: the rise of collaborative consumption. New York: Harper Business

Breidert, C., Hahsler, M., \& Reutterer, T. (2006). A review of methods for measuring willingness-to-pay. Innovative Marketing, 2(4), 8-32.

CamPerceived-benefits-composite II, D. T., \& Fiske, D. W. (1959). Convergent and discriminant validation by the multitrait-multimethod matrix. Psychological bulletin, 56(2), 81.

Crayton, T. J., \& Meier, B. M. (2017). Autonomous vehicles: Developing a public health research agenda to frame the future of transportation policy. Journal of Transport \& Health.

Chan, C. Y. (2017). Advancements, prospects, and impacts of automated driving systems. International Journal of Transportation Science and Technology, 6(3), 208-216.

Davis, F. D., Bagozzi, R. P., \& Warshaw, P. R. (1989). User acceptance of computer technology: a comparison of two theoretical models. Management science, 35(8), 982-1003. 
Davies, A. R., Edwards, F., Marovelli, B., Morrow, O., Rut, M., \& Weymes, M. (2017). Making visible: Interrogating the performance of food sharing across 100 urban areas. Geoforum, 86, 136-149.

Daziano, R. A., Sarrias, M., \& Leard, B. (2017). Are consumers willing to pay to let cars drive for them? Analyzing response to autonomous vehicles. Transportation Research Part C: Emerging Technologies, 78, 150-164.

Daziano, R. A., \& Bolduc, D. (2013). Incorporating pro-environmental preferences towards green automobile technologies through a Bayesian hybrid choice model. Transportmetrica A: Transport Science, 9(1), 74-106.

Duarte, F., \& Ratti, C. (2018). The impact of autonomous vehicles on cities: A review. Journal of Urban Technology, 25(4), 3-18.

Elder, J. P., Lytle, L., Sallis, J. F., Young, D. R., Steckler, A., Simons-Morton, D., ... \& Webber, L. (2007). A description of the social-ecological framework used in the trial of activity for adolescent girls (TAAG). Health education research, 22(2), 155-165.

Eves, F., Hoppéa, R., \& McLaren, L. (2003). Prediction of specific types of physical activity using the theory of planned behavior. Journal of Applied Biobehavioral Research, 8(2), 7795.

Ewing, R., \& Cervero, R. (2010). Travel and the built environment: a meta-analysis. Journal of the American planning association, 76(3), 265-294.

Fagnant, D. and K. Kockelman (2014) Environmental Implications for Autonomous Shared Vehicles, Using Agent-Based Model Scenarios. Transportation Research Part C 40: 1-20 13.

Fagnant, D. J., \& Kockelman, K. M. (2015). Dynamic ride-sharing and optimal fleet sizing for a system of shared autonomous vehicles. In Transportation Research Board 94th Annual Meeting (No. 15-1962).

French, D. P., Sutton, S., Hennings, S. J., Mitchell, J., Wareham, N. J., Griffin, S., \& Kinmonth, A. L. (2005). The importance of affective beliefs and attitudes in the theory of planned behavior: Predicting intention to increase physical activity. Journal of Applied Social Psychology, 35(9), 1824-1848

Gandia, R. M., Antonialli, F., Cavazza, B. H., Neto, A. M., Lima, D. A. D., Sugano, J. Y., ... \& Zambalde, A. L. (2019). Autonomous vehicles: scientometric and bibliometric review. Transport Reviews, 39(1), 9-28.

Gansky, L. (2010). The mesh: Why the future of business is sharing. Penguin. New York, USA

Gliem, J. A., \& Gliem, R. R. (2003). Calculating, interpreting, and reporting Cronbach's alpha reliability coefficient for Likert-type scales. Midwest Research-to-Practice Conference in Adult, Continuing, and Community Education. 
http://s3.spanglefish.com/s/8287/documents/psychological\%20measurement/cronbach\%2 Oalpha.pdf Accessed 26/07/2018

Gollnhofer, J. F., Hellwig, K., \& Morhart, F. (2016). Fair Is Good, but What Is Fair? Negotiations of Distributive Justice in an Emerging Nonmonetary Sharing Model. Journal of the Association for Consumer Research, 1(2), 226-245

Haboucha, C. J., Ishaq, R., \& Shiftan, Y. (2017). User preferences regarding autonomous vehicles. Transportation Research Part C: Emerging Technologies, 78, 37-49.

Hardman, S., Berliner, R., \& Tal, G. (2018). Who will be the early adopters of automated vehicles? Insights from a survey of electric vehicle owners in the United States. Transportation Research Part D: Transport and Environment. https://doi.org/10.1016/j.trd.2018.12.001

Hamari, J., Sjöklint, M., \& Ukkonen, A. (2016). The sharing economy: Why people participate in collaborative consumption. Journal of the Association for Information Science and Technology, 67(9), 2047-2059

Hair, J. F., Black, W. C., Babin, B. J., Anderson, R. E., \& Tatham, R. L. (2006). Multivariate data analysis (Vol. 5, No. 3, pp. 207-219). Upper Saddle River, NJ: Prentice hall.

Hashimoto, Y., Gu, Y., Hsu, L. T., Iryo-Asano, M., \& Kamijo, S. (2016). A probabilistic model of pedestrian crossing behavior at signalized intersections for connected

vehicles. Transportation research part C: emerging technologies, 71, 164-181.

Haustein, S., and M. Hunecke (2007). Reduced use of environmentally friendly modes of transportation caused by perceived mobility necessities: An extension of the theory of planned behavior. Journal of Applied Social Psychology 37: 1856-1883.

Henseler, J., Ringle, C. M., \& Sarstedt, M. (2015). A new criterion for assessing discriminant validity in variance-based structural equation modeling. Journal of the academy of marketing science, 43(1), 115-135.

Karvonen, A., Cugurullo, F., \& Caprotti, F. (Eds.). (2018). Inside Smart Cities: place, politics and urban innovation. Routledge, London

Kline, R.B.(2015) Principles and Practice of Structural Equation Modeling, 3rd ed.; Guilford: New York, NY, USA.

Kroesen, M., \& Chorus, C. (2018). The role of general and specific attitudes in predicting travel behavior-A fatal dilemma?. Travel Behaviour and Society, 10, 33-41.

Kyriakidis, M., Happee, R., \& de Winter, J. C. (2015). Public opinion on automated driving: Results of an international questionnaire among 5000 respondents. Transportation research part F: traffic psychology and behaviour, 32, 127-140. 
Lavasani, M., Jin, X., \& Du, Y. (2016). Market penetration model for autonomous vehicles based on previous technology adoption experiences. In Transportation Research Board 95th Annual Meeting (No. 16-2284).

Lavieri, P. S., Garikapati, V. M., Bhat, C. R., Pendyala, R. M., Astroza, S., \& Dias, F. F. (2017). Modeling Individual Preferences for Ownership and Sharing of Autonomous Vehicle Technologies. $9^{\text {th }}$ Annual Meeting of the Transportation Research Board (No. 17-05843).

Litman, T. (2017). Autonomous vehicle implementation predictions. Implications for Transport Planning. Presented at the 2015 Transportation Research Board Annual Meeting url: http://leempo.com/wp-content/uploads/2017/03/M09.pdf Accessed 26/07/2018

McFadden, D. (1973). Conditional logit analysis of qualitative choice behaviour. In Frontiers of Econometrics, edited. by P. Zarembka. New York: Academic Press.

McLaren, D., \& Agyeman, J. (2015). Sharing cities: a case for truly smart and sustainable cities. MIT Press.

McLeroy, K. R., Bibeau, D., Steckler, A., \& Glanz, K. (1988). An ecological perspective on health promotion programs. Health education quarterly, 15(4), 351-377.

Milfont, T. L., \& Duckitt, J. (2010). The environmental attitudes inventory: A valid and reliable measure to assess the structure of environmental attitudes. Journal of environmental psychology, 30(1), 80-94.

Milakis, D., Van Arem, B., \& Van Wee, B. (2017). Policy and society related implications of automated driving: A review of literature and directions for future research. Journal of Intelligent Transportation Systems, 1-25.

Moore, G. C., \& Benbasat, I. (1991). Development of an instrument to measure the perceptions of adopting an information technology innovation. Information systems research, 2(3), 192-222.

Mont, O. (2004). Institutionalisation of sustainable consumption patterns based on shared use. Ecological economics, 50(1), 135-153.

Næss, P. (2015). Built environment, causality and travel. Transport Reviews, 35(3), 275-291.

Nair, G. S., Astroza, S., Bhat, C. R., Khoeini, S., \& Pendyala, R. M. (2017). An application of a rank ordered probit modeling approach to understanding level of interest in autonomous vehicles. http://www.caee.utexas.edu/prof/Bhat/ABSTRACTS/RankOrderedProbitModel.pdf retrieved 10/11/2017 Accessed 26/07/2018

NHTSA (2013), Preliminary Statement of Policy Concerning Automated Vehicles, National Highway Traffic Safety Administration (www.nhtsa.gov). 
Plouffe, C. R., Hulland, J. S., \& Vandenbosch, M. (2001). Richness versus parsimony in modeling technology adoption decisions-understanding merchant adoption of a smart card-based payment system. Information systems research, 12(2), 208-222.

Pudāne, B., Rataj, M., Molin, E. J., Mouter, N., van Cranenburgh, S., \& Chorus, C. G. (2018). How will automated vehicles shape users' daily activities? Insights from focus groups with commuters in the Netherlands. Transportation Research Part D: Transport and Environment.

Rogers E, M. (2000). Diffusion of innovations. New York: The Free Press

Rogers E, M. (1995). Diffusion of innovations. (Fourth Edition) New York: The Free Press

Sallis, J. F., Owen, N., and Fisher, E. B., (2008). Ecological models of health behaviour. In K. V. Karen Glanz, Barbara K. Rimer (Ed.), Health Behaviour and Health Education: Theory, Research, and Practice, 4th edition (4th Edition, pp. 465-485). http://doi.org/10.7326/00034819-116-4-350_1

Sanbonmatsu, D. M., Strayer, D. L., Yu, Z., Biondi, F., \& Cooper, J. M. (2018). Cognitive underpinnings of beliefs and confidence in beliefs about fully automated vehicles. Transportation research part F: traffic psychology and behaviour, 55, 114-122.

Schonberger B and Gutmann S (2013), A Self-Driving Future: At the Intersection of Driverless Cars and Car Sharing, Sightline Institute (www.sightline.org); at http://daily.sightline.org/2013/06/04/a-self-driving-future. Accessed 26/07/2018

Sigurdardottir, S. B., Kaplan, S., Møller, M., \& Teasdale, T. W. (2013). Understanding Adolescents' intentions to commute by car or bicycle as adults. Transportation research part D: transport and environment, 24, 1-9.

Sivak M. and Schoettle B (2015), Potential Impact of Self-Driving Vehicles on Household Vehicle Demand and Usage, Sustainable Worldwide Transportation Program, Transportation Research Institute, The University of Michigan. Report No. UMTRI-2015-3

Sutton, S., French, D. P., Hennings, S. J., Mitchell, J., Wareham, N. J., Griffin, S., \& Kinmonth, A. L. (2003). Eliciting salient beliefs in research on the theory of planned behaviour: The effect of question wording. Current Psychology, 22(3), 234-251

Sun, G., Acheampong, R. A., Lin, H., \& Pun, V. C. (2015). Understanding walking behavior among university students using theory of planned behavior. International journal of environmental research and public health, 12(11), 13794-13806.

Umberger, R. J. (2016). Who Will Be the First to Buy Autonomous Vehicles? An Application of Everett Rogers' Diffusion of Innovations Theory. CMC Senior Theses. 1267. https://scholarship.claremont.edu/cmc theses/1267

Urban, G. L., \& Von Hippel, E. (1988). Lead user analyses for the development of new industrial products. Management science, 34(5), 569-582. 
Venkatesh, V., \& Davis, F. D. (2000). A theoretical extension of the technology acceptance model: Four longitudinal field studies. Management science, 46(2), 186-204.

Venkatesh, V., Morris, M. G., Davis, G. B., \& Davis, F. D. (2003). User acceptance of information technology: Toward a unified view. MIS quarterly, 425-478.

Wadud, Z., MacKenzie, D., \& Leiby, P. (2016). Help or hindrance? The travel, energy and carbon impacts of highly automated vehicles. Transportation Research Part A: Policy and Practice, 86, 1-18.

Woldeamanuel, M., \& Nguyen, D. (2018). Perceived benefits and concerns of autonomous vehicles: An exploratory study of millennials' sentiments of an emerging market. Research in Transportation Economics. https://doi.org/10.1016/i.retrec.2018.06.006

Wu, J., Liao, H., Wang, J. W., \& Chen, T. (2019). The role of environmental concern in the public acceptance of autonomous electric vehicles: A survey from China. Transportation Research Part F: Traffic Psychology and Behaviour, 60, 37-46.

Zhang, W., \& Guhathakurta, S. (2017). Parking spaces in the age of shared autonomous vehicles: How much parking will we need and where. In Transportation Research Board 96th Annual Meeting. 